\title{
Lineage-affiliated transcription factors bind the Gata3 Tce1 enhancer to mediate lineage-specific programs
}

\author{
Sakie Ohmura, ${ }^{1}$ Seiya Mizuno, ${ }^{2}$ Hisashi Oishi, ${ }^{2}$ Chia-Jui Ku, ${ }^{1}$ Mary Hermann, ${ }^{1}$ Tomonori Hosoya, ${ }^{1}$ Satoru Takahashi, ${ }^{2}$ and \\ James Douglas Engel ${ }^{1}$ \\ 'Department of Cell and Developmental Biology, University of Michigan Medical School, Ann Arbor, Michigan, USA. ²Department of Animal Sciences, Tsukuba University School of Medicine, Tsukuba, Japan.
}

\begin{abstract}
The transcription factor GATA3 is essential for the genesis and maturation of the T cell lineage, and GATA3 dysregulation has pathological consequences. Previous studies have shown that CATA3 function in T cell development is regulated by multiple signaling pathways and that the Notch nuclear effector, RBP-J, binds specifically to the Gata3 promoter. We previously identified a T cell-specific Gata3 enhancer (Tce1) lying $\mathbf{2 8 0 ~ k b ~ d o w n s t r e a m ~ f r o m ~ t h e ~ s t r u c t u r a l ~ g e n e ~ a n d ~}$ demonstrated in transgenic mice that Tce1 promoted T lymphocyte-specific transcription of reporter genes throughout T cell development; however, it was not clear if Tce1 is required for Gata3 transcription in vivo. Here, we determined that the canonical Gata3 promoter is insufficient for Gata3 transcriptional activation in T cells in vivo, precluding the possibility that promoter binding by a host of previously implicated transcription factors alone is responsible for Gata 3 expression in T cells. Instead, we demonstrated that multiple lineage-affiliated transcription factors bind to Tce1 and that this enhancer confers T lymphocyte-specific Gata3 activation in vivo, as targeted deletion of Tce1 in a mouse model abrogated critical functions of this T cell-regulatory element. Together, our data show that Tce1 is both necessary and sufficient for critical aspects of Gata3 T cell-specific transcriptional activity.
\end{abstract}

\section{Introduction}

The independent lineages of mature hematopoietic cells are initially generated from stem cells that are extrinsically and intrinsically regulated to traverse multiple, distinct developmental stages. A host of tissue- and stage-affiliated transcription factors and signaling pathways plays essential roles in achieving the final differentiated state of each hematopoietic lineage. The appropriate contribution of different factors and signaling pathways to each lineage-specific transcriptional network ultimately determines the developmental fate and activity of each hematopoietic cell type.

Following the circulation of immature hematopoietic cells from the bone marrow to the thymus, early $\mathrm{T}$ lineage progenitors (ETPs) are generated and undergo development into double-negative cells (stages DN2 to DN4), in which neither the CD4 nor the CD8 coreceptor is expressed. $\beta$-Selection, one of several critical steps during T cell development, occurs at the DN3 stage, and only thymocytes that successfully rearrange the T cell receptor (TCR) $\beta$ locus (and therefore express a functional pre-T $\alpha / \mathrm{TCR} \beta$ complex) are licensed to differentiate further and transition to the DN4 and immature single-positive (SP; $\mathrm{CD}^{-}{ }^{-} \mathrm{CD}^{+}{ }^{+} \mathrm{TCRb}^{\mathrm{lo}}$ ) stages. As those immature SP cells become double positive (DP) for the CD4 and $\mathrm{CD} 8$ coreceptors, the TCR $\alpha$ locus rearranges. DP cells that express a functional TCR $\alpha \beta$ receptor on their cell surface then undergo positive selection and move into the $\mathrm{CD} 4^{+} \mathrm{CD} 8^{\text {lo }}$ intermediate stage. $\mathrm{CD} 4^{+} \mathrm{CD} 8^{\text {lo }}$ cells are still uncommitted to a specific $\mathrm{T}$ cell cytotoxic or helper function, and thus CD4 versus CD8 lineage choice occurs at this stage. Persistent TCR signaling contributes to

Conflict of interest: The authors have declared that no conflict of interest exists. Submitted: July 24, 2015; Accepted: December 10, 2015.

Reference information: J Clin Invest. 2016;126(3):865-878. doi:10.1172/JCI83894
CD4 lineage fate, and cells differentiate into CD4 SP cells, while cessation of TCR signaling and initiation of IL-7 signaling contribute to CD8 lineage fate. CD4 and CD8 cells then exit the thymus and circulate to peripheral lymphoid organs where they can acquire effector functions as either helper T cells (CD4 lineage) or cytotoxic T cells (CD8 lineage) (reviewed in refs. 1, 2).

Following our original identification of transcription factor GATA3 in chicken, mouse, and human cells $(3,4)$, we and others showed that it is expressed throughout $\mathrm{T}$ cell development, although its level varies significantly between stages, from abundant expression in CD4 cells to quite low expression in CD8 cells (5-11). Numerous studies have demonstrated the crucial importance and essential contributions of GATA3 to different stages of T cell development, in ETP (12), DN1 (13), the DN3-to-DN4 transition (14), CD4 cells $(14,15)$, and Th2 cells $(16,17)$. Although GATA3 is dispensable for the initial generation of CD8 cells, it is required for their final maturation, maintenance, and function $(18,19)$. In addition to the T cell lineage, GATA3 plays important roles in the innate immune system (20-22) and in NK cell development $(23,24)$. In contrast, B lymphocyte development requires Gata3 repression (25).

Although its pervasive expression is essential throughout normal $\mathrm{T}$ cell development, forced expression or underexpression of GATA3 can trigger pathological consequences (26-30), for example, generating $\mathrm{T}$ cell lymphoma in transgenic $(\mathrm{Tg})$ mice (27) or elevated susceptibility to allergic airway inflammation (31, 32). Additionally, GATA 3 is aberrantly expressed in Hodgkin's lymphoma (33) and controls cytokine expression, which plays an important role in the pathogenesis of Hodgkin's disease (34). Haploinsufficient GATA3 mutation in humans leads to HDR syndrome (hypoparathyroidism, sensorineural deafness, and renal disease; 
ref. 35). Collectively, these data highlight the conclusion that normal $\mathrm{T}$ cell development requires quantitatively and qualitatively stringent control over GATA3 expression.

We previously reported the identification of a $\mathrm{T}$ cell-specific Gata3 enhancer, which we originally named TCE-7.1 (referred to hereafter as Tce1) (36). Tce1 is a 7.1-kb segment of the locus located $280 \mathrm{kbp} \mathrm{3'}$ to the Gata3 structural gene. We showed that this enhancer induces $\mathrm{T}$ lymphocyte-specific transcription of reporter genes throughout $\mathrm{T}$ cell development and enhances NK cell expression (36). However, multiple additional mechanistic questions emerged from that study. For example, is Tce1 necessary for Gata3 regulation of $\mathrm{T}$ cell development in vivo or does it act in a redundant fashion with additional currently unidentified cis elements? What is the mechanism of action of Tce1 (that is, how does Tce1 differentially regulate the precise differential abundance of GATA3 at multiple T cell developmental stages)? Finally, what transcription factors elicit appropriate Gata3 transcriptional responses in a stage-specific manner through this enhancer?

Here, we report that homozygous genetic loss of Tce1 in vivo using CRISPR/Cas9-mediated genome editing impairs at least two critical T cell stages: the initial generation of ETP and the development of CD4 lymphocytes. We also show that Tce1 contains a critical enhancer sequence defined by a 1.2-kbp core fragment that regulates transcription in developmental stages from ETP through to naive T cells. Previous studies showed that Gata3 is regulated by transcription factors HEB $(37,38)$, T cell factor 1 (TCF-1) (39), and RBP-J/CSL (40), all of which bind to the promoter. We show that the binding of those factors to the Gata3 promoter alone is insufficient to confer T cell-specific activation to Gata3 but that the same factors also bind avidly within Tce1, providing a possible explanation for how Gata3 regulation mediated through Tce1 can be responsive to the Wnt (41) and Notch (40) signaling pathways.

\section{Results}

Tce1 is necessary for ETP and CD4 T cell development. One of the central questions that emerged from our previous study (36), which showed that Tce1 was sufficient for reporter gene T cellspecific activation throughout $\mathrm{T}$ cell development, was whether Tce1 is also necessary for Gata3 activation in vivo. To address this question, we targeted the genomic locus using CRISPR/Cas9 guide RNAs (gRNAs) (42) corresponding to sequences on either side of the $7.1 \mathrm{kbp}$ that define the boundaries of Tce 1 and, at the same time, introduced single-stranded oligonucleotides bearing genomic homology that would additionally incorporate loxP sequences into the two targeted sites (Figure 1A and Supplemental Figure 1; supplemental material available online with this article; doi:10.1172/JCI83894DS1). gRNAs were selected after examination of the genome for similar sequences that had the fewest potentially related off-target homologies. In this manner, we anticipated, after injection of the constructs into fertilized murine ova, the generation of germ line mutants in which Tce1 would be unaltered in function until conditional deletion of the enhancer after Cre recombinase excision. Both gRNA and CRISPR/Cas9 vectors were microinjected into 441 fertilized oocytes of $\mathrm{F}_{2}$ animals generated by crossing C57BL/6J males already bearing the Mx1-Cre $\operatorname{Tg}$ (43) with wild-type SJL females; 77 live pups were screened by PCR for mutations incorporated at the gRNA-targeted sequences.
The results of analysis of these offspring indicated that 3 of the pups displayed evidence for incorporation of both loxP sites (either in cis or trans), while 3 of the animals had heterozygous deletions and 1 of the animals had homozygous deletions of the entire 7.1kbp sequence lying between the two gRNA sites (Supplemental Figure 2). Since the two gRNAs targeted for the $5^{\prime}$ and $3^{\prime}$ ends of Tce1 were injected at the same time, double-strand breaks probably occurred simultaneously at both ends and resulted in deletion of Tce1 by nonhomologous end joining, as previously reported (44). Sequencing across the two sites in amplified genomic DNA under conditions that would not detect the germ line configuration confirmed deletion of Tce1 from at least one allele (Supplemental Figure 2). In this study, we focused on the deleted alleles and did not further analyze the potential floxed alleles.

Next, we examined thymocytes, peripheral blood, and spleens for possible alterations in hematopoietic and $\mathrm{T}$ cell development and/or Gata3 mRNA expression that could be detected as a consequence of Tce1 loss in both homozygous and heterozygous $\mathrm{F}_{3}$ and subsequent generation mice (Figure 1, B-D, and Supplemental Figure 3), as previously shown (12). As anticipated, homozygous loss of Tce1 ( $\left.\mathrm{Tce}^{-/-}\right)$led to a reduction in the number of ETPs $(62 \%$ of that of heterozygous controls), and Gata3 mRNA in the remaining ETPs was only $52 \%$ of that of controls (Figure 1B). In contrast, the number of $\mathrm{Tce}^{-/-} \mathrm{DN} 2$ and DN3 stage cells was unaltered compared with that of controls, although Gata3 mRNA levels in DN2 thymocytes were reduced ( $83 \%$ of that of heterozygous controls; Figure 1B). This modest reduction in the number of early stage $\mathrm{T}$ cells in $\mathrm{Tce}^{-/-}$mice is similar to the phenotype observed in Gata3 hypomorphic mutants, which express low levels (10\%-20\% of that of wild-type animals) of a GATA3-EGFP fusion protein in thymocytes of adoptively reconstituted animals (12). In $\mathrm{Tcel}^{-/-} \mathrm{DN} 4$ and DP stages, Gata 3 mRNA was reduced to $55 \%$ and $45 \%$ of that of controls, respectively, while the total number of cells was normal.

The data shown here demonstrate that $\mathrm{T}$ cell development is severely affected in $\mathrm{Tce}^{1^{-/}}$mice. The number of CD4 SP thymocytes was reduced to $30 \%$ of that of controls, and Gata3 mRNA abundance in the surviving CD4 thymocytes was reduced to $42 \%$ of that of control values (Figure 1B), while, in contrast, the numbers of CD4 SP thymocytes and mRNA levels of Gata3 in CD8 $\mathrm{T}$ cells were comparable in $\mathrm{Tce}^{-1-}$ and heterozygous control mice (Figure 1B). Similarly, the number of CD4 T cells in $\mathrm{Tcel}^{-/-}$mice was reduced in the peripheral blood (30\% of that of controls, Figure 1C) and spleens (39\% of that of controls, Figure 1D) in comparison to those in controls, while the number of peripheral CD8 $\mathrm{T}$ cells was unaffected. The CD4 T cell-specific defect observed in $\mathrm{Tce}^{1 /-}$ mutant mice is consistent with previous studies in which the Gata3 gene was conditionally ablated by a Cd4-Cre $\operatorname{Tg}(14,15)$. The normal level of Gata3 mRNA found in surviving peripheral CD4 $\mathrm{T}$ cells suggests that cells retaining less abundant GATA3 expression cannot survive or that their proliferation is retarded at this stage. To further characterize the peripheral CD4 $\mathrm{T}$ cells generated in the absence of Tce1, we analyzed expression of CD44 and CD62L, which can distinguish naive $\mathrm{T}$ cells from memory $\mathrm{T}$ cells (45). While the $\mathrm{CD} 44^{\mathrm{lo}} \mathrm{CD} 62 \mathrm{~L}^{+}$naive $\mathrm{T}$ cell number was significantly reduced in splenic CD4 T cells isolated from $\mathrm{Tce}^{-1-}$ mice when compared with that in heterozygous controls (Supplemental Figure 4 ), the CD $44{ }^{\text {hi }} \mathrm{CD} 62 \mathrm{~L}^{-}$memory $\mathrm{T}$ cell number was compa- 
A

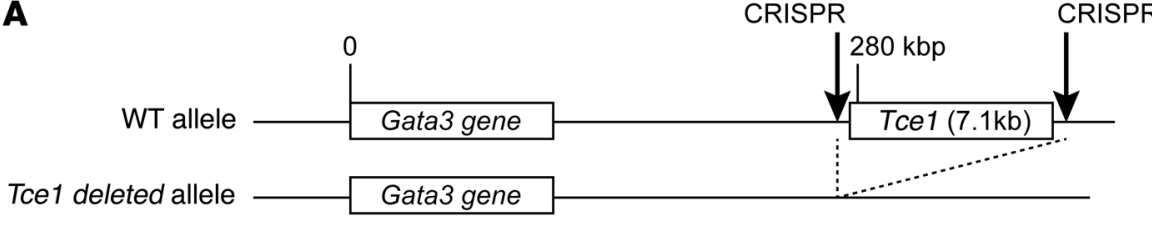

B Thymus
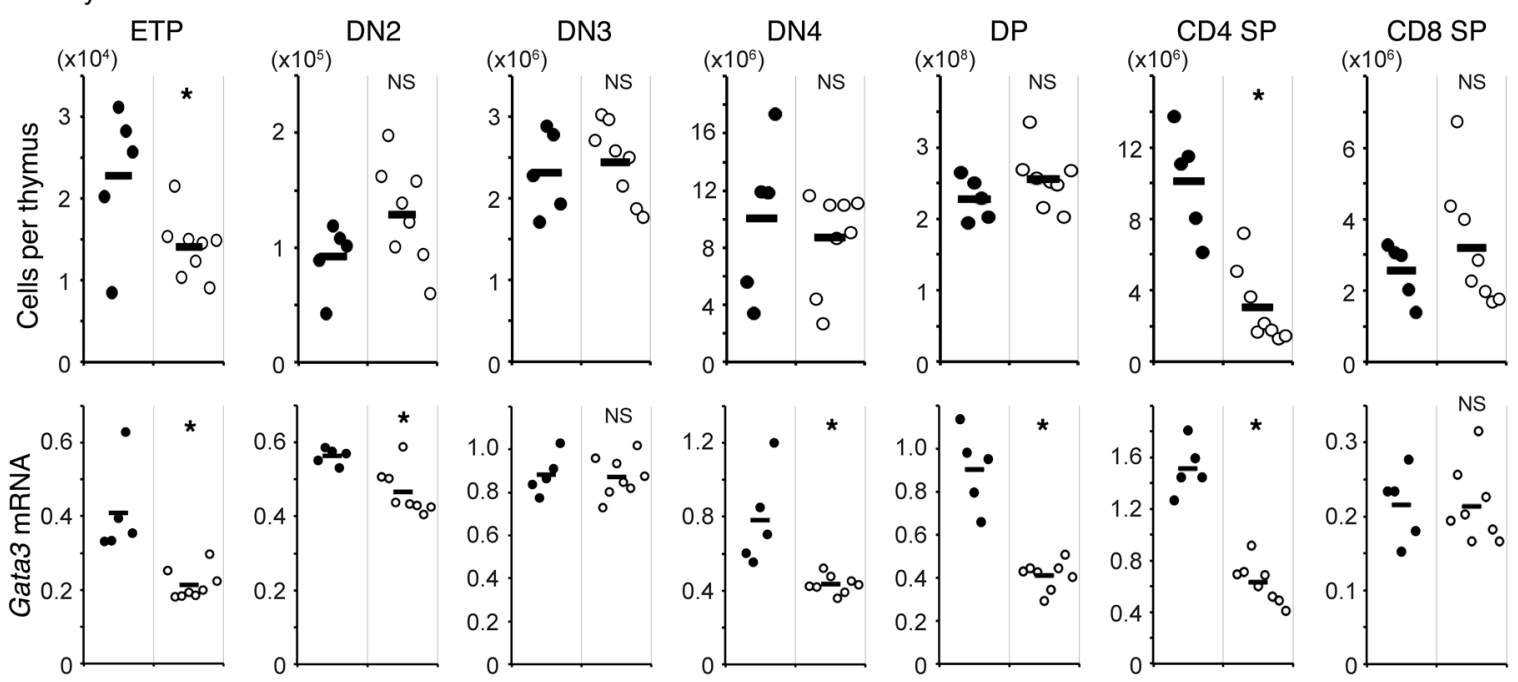

C

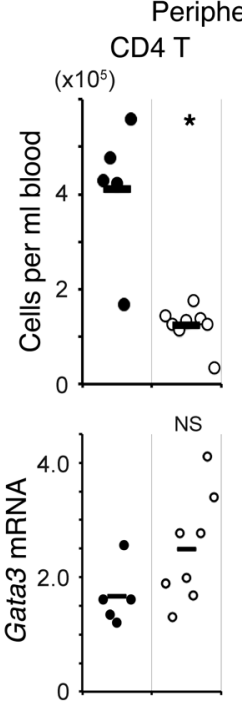

Peripheral blood

CD8 T

$\left(x 10^{5}\right)$
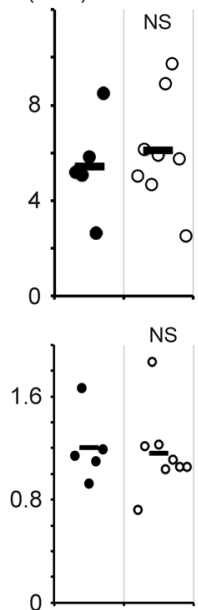

D

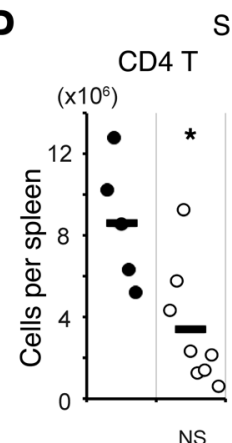

Spleen
CD8 T
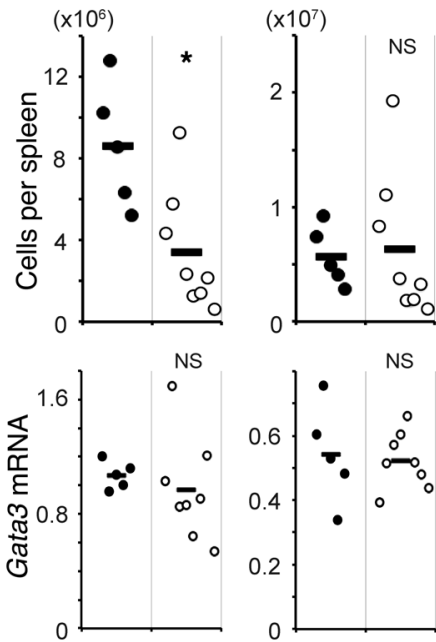

Figure 1. In vivo genome deletion of Tce1. (A) Two CRISPR/Cas9 plasmids expressing gRNAs that correspond to sequences surrounding the $7.1 \mathrm{kbp}$ that define the boundaries of Tce1 were coinjected into mouse fertilized oocytes. Tce1-deleted mutant allele founder $\left(F_{0}\right)$ mice were intercrossed to obtain homozygous deletion mutant mice. (B) Thymocytes, (C) peripheral blood cells, and (D) splenocytes isolated from $F_{2}$ animals at 5 to 6 weeks of age bearing homozygous (white circle) or heterozygous (black circle) deletions of Tce1 were analyzed for cell surface expression of T cell stage-specific markers. The

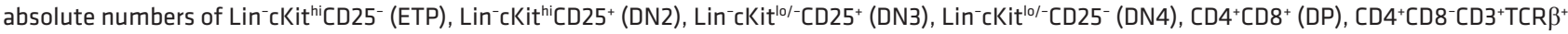
(CD4 SP), and CD4-CD8+CD3+TCR $\beta^{+}$(CD8 SP) thymocytes are shown at the top. Each stage of T cells was isolated by flow cytometry and analyzed for the expression of Gata3 mRNA, as normalized to Hprt by qRT-PCR. Each circle represents an individual mouse, and black bars represent the average for each genotype. Data are representative of the summary of 2 independent experiments. ${ }^{*} P<0.05$ by Student's $t$ test.

rable in the two genotypes. The data suggest that compensatory expansion or accumulation of memory $\mathrm{T}$ cells in Tce1-deleted mutants must exist. The data clearly demonstrate that $\mathrm{CD} 4 \mathrm{~T}$ cell development is severely compromised by deletion of Tce1 in mice.

Collectively, the data demonstrate that Tce1 is necessary for Gata3 gene expression and therefore $\mathrm{T}$ cell development in
ETP and CD4 stages in the thymus as well as in CD4 T cells in the peripheral blood and spleen. Tce1 also contributes to Gata3 expression in DN4 and DP stage cells, even though the number of those cells that accumulate is normal whether Tce1 is present or absent. We concluded that Tce1 is a critical regulator of the Gata3 gene in a subset of thymocytes. Since the phenotypes 
A

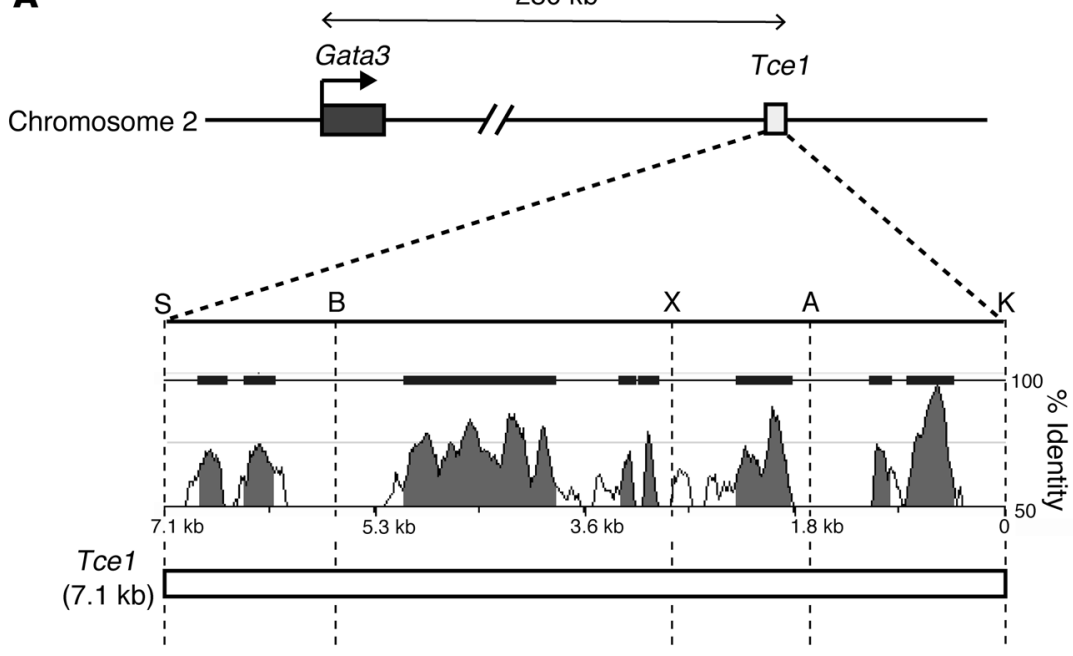

B

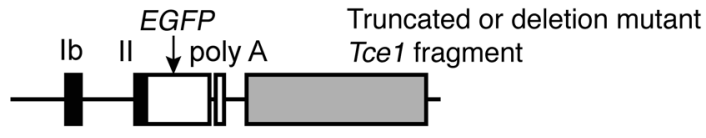

Figure 2. Truncation and deletion mutants of Tce1. (A) Diagrams of the mouse Gata3 locus and Tce1. Sequence homology between mouse and human Tce1 sequences is depicted as a Manhattan diagram. Restriction enzyme recognition sites Sal I (S), Bstll (B), Xhol (X), ApaLI (A), and Kpnl (K) are shown. The genome position of Tce1 is mm9 chr2, position 9,515,156 to 9,522,270. (B) The structure of the EGFP reporter plasmid used in this study is depicted.

was not possible. Each of the EGFP reporter plasmids was injected into fertilized ova to generate founder $\left(\mathrm{F}_{\mathrm{o}}\right) \mathrm{Tg}$ mice (referred to as $\mathrm{Tg}^{2.9}$ and $\mathrm{Tg}^{4.2}$ mice, respectively), since we had previously demonstrated that $\mathrm{T}$ cell cis element(s) could be rapidly and efficiently identified by founder analysis (36). One important fact to keep in mind for this analysis is that the Tce1-driven EGFP reporter transgenic mouse line $\left(\mathrm{Tg}^{\mathrm{Tcel}}\right)$ is a stable, established $\mathrm{Tg}$ line, while $\mathrm{Tg}^{2.9}$ mice and all other $\mathrm{Tg}$ mice examined in this study are founders. Therefore, it is extremely difficult to quantitaobserved in $\mathrm{Tce}^{-/-}$mutant mice are milder than those in mice in which the Gata3 gene itself is ablated and since diminished accumulation of GATA3 transcripts was detected in the affected stages of $\mathrm{T}$ cells, a redundant but currently unidentified second enhancer(s) appears to at least partially compensate for the loss of in Tce1 in vivo (see Discussion).

Dissection of the molecular architecture that confers Tce1 activity during thymocyte development. Given that homozygous deletion of Tcel from the genome resulted in compromised T cell development (Figure 1) and that Tce1 is capable of driving transcription of a reporter gene at all $\mathrm{T}$ cell developmental stages (36), one can imagine several possibilities for how Tce1 might function. For example, Tce1 might contain only a single cis element that is capable of regulating transcription at all $\mathrm{T}$ cell developmental stages in response to modulated signals received from signal-activated transcription factors, as they respond to intracellular or extracellular differentiation signals. Alternatively, the 7.1-kbp Tce1 might harbor multiple cis elements, each of which additively or synergistically contributes to distinct stages of $\mathrm{T}$ cell development.

In order to experimentally distinguish among these possibilities, we prepared multiple fluorescent reporter constructs, each directed by the Gata3 $1 b$ promoter (46) and bearing various Tce1 fragments (Figure 2B, shown in detail in Figure 3A, Figure 4A, Figure $5 \mathrm{~A}$, Figure $6 \mathrm{~A}$, and Figure $7 \mathrm{~A}$ ). $\mathrm{Tg}$ animals whose transcription was directed by an individual fragment of Tce1 (e.g., the 1.2-kb fragment shown in Figure $4 \mathrm{~A}$ ) are designated as such (e.g., $\left.\operatorname{Tg}^{1.2}\right)$, while deletion of each part of Tcel from the whole is designated by a preceding $\Delta$ (e.g., $\operatorname{Tg}^{\Delta 1.2}$, Figure $5 \mathrm{~A}$ ). The details for plasmid constructions are described in the Supplemental Methods.

We first bisected $T c e 1$ into two $2.9-\mathrm{kb}$ and $4.2-\mathrm{kb}$ fragments, respectively (Figure 3A). Both fragments contained multiple conserved noncoding sequences (CNSs; Figure 2A) as well as dozens of putative binding sites for $\mathrm{T}$ cell-affiliated transcription factors, so an a priori evaluation of their transcriptional potential in $\mathrm{T}$ cells tively compare data among different founder animals or between founders and lines.

When we analyzed reporter gene expression in $\mathrm{T}$ cells from peripheral blood, we found that EGFP was expressed in CD4 T cells in the majority of $\mathrm{Tg}^{2.9}$ mice but not in $\mathrm{Tg}^{4.2}$ mice (Table 1 and Supplemental Figure 5A). Furthermore, and as is also true for $\mathrm{Tg}^{\text {Tcel }}$ mice, EGFP expression was observed in $\mathrm{Tg}^{2.9}$ animals at multiple stages, including ETP and CD4 T cells (Figure 3 and Table 2). In addition to $\alpha \beta T C R^{+} \mathrm{T}$ cells, $\gamma \delta \mathrm{TCR}^{+}$thymocytes expressed EGFP (Supplemental Figure 6 and Supplemental Table 1). In contrast, EGFP expression was never detected in thymocytes from $\mathrm{Tg}^{4.2}$ mice (Figure 3 and Table 2), and neither group of founders expressed EGFP in other hematopoietic lineages (Supplemental Table 2). These results show that the 2.9-kb fragment, but not the $4.2-\mathrm{kb}$ fragment, is sufficient to direct transcription of reporter genes throughout thymocyte development.

Since the 2.9-kb Tce1 fragment harbors two clusters of CNSs (Figure 2A), we wondered whether either could function as an independent $\mathrm{T}$ cell-specific enhancer and whether both are required for transcription in $\mathrm{T}$ cells. Therefore, we bisected the

\section{Table 1. EGFP expression in the peripheral blood of $F_{0}$ Tg mice}

\begin{tabular}{lc}
$\mathrm{Tg}$ & No. CD4 \\
$\mathrm{Tg}^{2.9}$ & $\mathrm{ECFP}^{+} \mathrm{Tg}$ mice/no. Tg mice $\left(\mathrm{PCR}^{+}\right)$ \\
$\mathrm{Tg}^{4.2}$ & $9 / 14$ \\
$\mathrm{Tg}^{1.2}$ & $0 / 6$ \\
$\mathrm{Tg}^{1.7}$ & $4 / 7$ \\
$\mathrm{Tg}^{\Delta 1.2}$ & $0 / 4$ \\
$\mathrm{Tg}^{\Delta 1.7}$ & $0 / 7$ \\
$\mathrm{Tg}^{\Delta 1.5}$ & $10 / 14$ \\
$\mathrm{Tg}^{\Delta 2.7}$ & $20 / 24$ \\
\hline
\end{tabular}



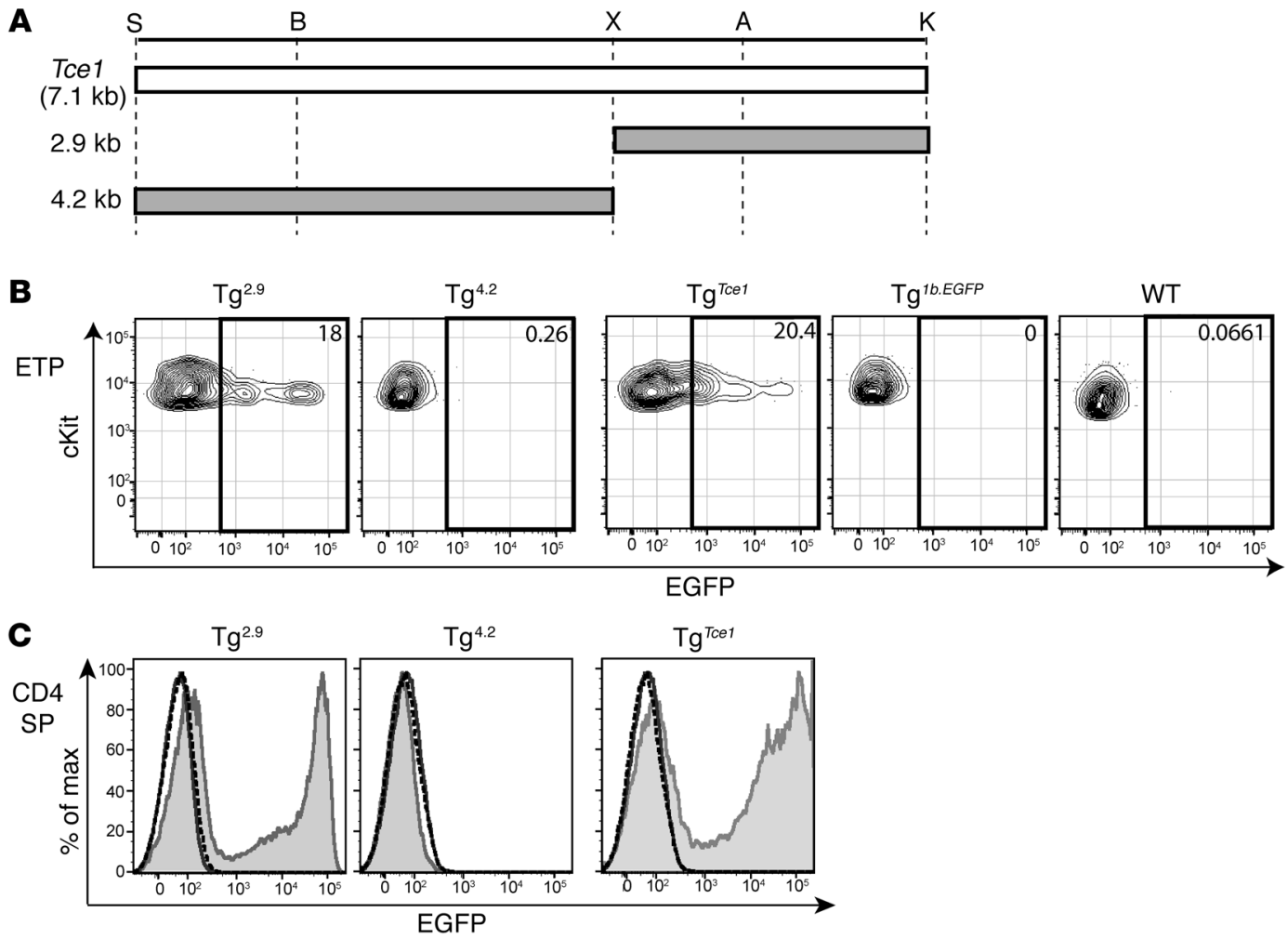

Figure 3. A 2.9-kb fragment of Tce1 drives thymocyte-specific transcription of reporter genes. (A) Illustration of truncated 2.9-kb and 4.2-kb Tce $1 \mathrm{frag}$ ments. Restriction enzyme recognition sites are shown. EGFP expression in (B) ETP and (C) CD4+CD8 ${ }^{-} \mathrm{TCR}^{+}$(CD4 SP) cells from Tg ${ }^{2.9}$, Tg ${ }^{4.2}, \mathrm{Tg}^{\text {Tee }}$, and Tg ${ }^{\text {1b.ECFP }}$ mice and in wild-type thymocytes. Note that $\mathrm{Tg}^{2.9}$ and $\mathrm{Tg}^{4.2}$ mice are $\mathrm{F}_{0}$ mice, while $\mathrm{Tg}^{\text {TCe1 }}$ and $\mathrm{Tg}^{16 . E C F P}$ mice are from $\mathrm{Tg}$ lines established previously. Data are representative of 2 independent experiments; the gray shaded histogram represents expression in $\mathrm{Tg}^{2.9}, \mathrm{Tg}^{4.2}$, or $\mathrm{Tg}^{\text {Tce }}$, respectively; the solid line histogram represents expression in $\mathrm{Tg}^{\text {1b.EGFP }}$; and the dashed line histogram represents expression in wild-type mice.

2.9-kb fragment into $1.2-\mathrm{kb}$ and $1.7-\mathrm{kb}$ subclones that contained the individual CNSs (Figure 2A and Figure 4A), used these to generate new $\mathrm{Tg}$ founders ( $\mathrm{Tg}^{1.2}$ and $\mathrm{Tg}^{1.7}$ mice), and analyzed peripheral blood from those $\mathrm{F}_{0}$ mice as before. We found that EGFP was expressed in the peripheral blood CD4 T cells in the majority of $\mathrm{Tg}^{1.2}$ mice, while EGFP expression was essentially absent in $\mathrm{Tg}^{1.7}$ mice (Table 1 and Supplemental Figure 5B). Detailed analyses of their thymocytes revealed that $\mathrm{Tg}^{1.2}$ mice again exhibited EGFP expression at multiple stages of thymopoiesis (Figure 4, B and C; Table 2; Supplemental Figure 6B; and Supplemental Table 1), and, as before, EGFP expression was not observed in other kinds of hematopoietic cells (Supplemental Table 2). Taken together, the data show that a 1.2-kb fragment within Tce1 contains multistage $\mathrm{T}$ cell enhancer activity and that this fragment is sufficient to drive the transcription of a reporter gene in all stages of thymocytes.

We next asked whether this 1.2-kb Gata3 Tce1 fragment was also necessary for the transcription of a reporter gene in T cells. To answer this question, we prepared another EGFP reporter plasmid in which the 1.2-kb sequence was deleted from full-length Tce1 (Figure 5A) and generated additional $\mathrm{F}_{0} \mathrm{Tg}$ mice ( $\operatorname{Tg}^{\Delta 1.2}$ mice). None of the $\mathrm{F}_{0} \operatorname{Tg}^{\Delta 1.2}$ mice expressed EGFP in peripheral CD 4 T cells (Table 1 and Supplemental Figure 5C) or in thymocytes (Figure 5, B and C), except possibly at the DN4 stage (Table 2). We also analyzed $\operatorname{Tg}^{\Delta 1.7}, \operatorname{Tg}^{\Delta 1.5}$, and $\operatorname{Tg}^{\Delta 2.7}$ mice and found that all of them expressed EGFP in peripheral CD4 T cells (Tables 1 and 2). Therefore, the EGFP expression in those mice confirmed that these sequences were not required for Tce1 enhancer activity in peripheral CD4 T cells. These data show that the $1.2-\mathrm{kb}$ T cell enhancer fragment within Tce1 is also necessary for reporter gene transcription in $\mathrm{T}$ cells and, taken together with the data shown in Figure 1, that this fragment functions as an enhancer core element in vivo for Gata3 T cell-specific transcription. The data also show that the extended Gata3 promoter, either alone or when combined with inactive fragments of Tce1, is not sufficient for T cell activation.

Transcription of Gata3 in Th2 cells requires cooperation of multiple elements within Tce1. GATA3 is necessary for the differentiation and function of Th2 cells (5), and we have shown that Tce1 can
Table 2. EGFP expression at each thymocyte developmental stage in $F_{0} \operatorname{Tg}$ mice

$\operatorname{Tg}$

$\begin{array}{lccccccc} & \text { ETP } & \text { DN2 } & \text { DN3 } & \text { DN4 } & \text { DP } & \text { CD4 SP } & \text { CD8 SP } \\ \mathrm{Tg}^{2.9} & 7 / 8^{A} & 6 / 8^{A} & 8 / 8^{A} & 8 / 8^{A} & 8 / 8^{A} & 8 / 8^{A} & 8 / 8^{A} \\ \mathrm{Tg}^{4.2} & 0 / 6 & 0 / 6 & 0 / 6 & 0 / 6 & 0 / 6 & 0 / 6 & 0 / 6 \\ \mathrm{Tg}^{1.2} & 4 / 7 & 2 / 7 & 3 / 7 & 4 / 7 & 4 / 7 & 4 / 7 & 4 / 7 \\ \mathrm{Tg}^{1.7} & 0 / 4 & 0 / 4 & 0 / 4 & 0 / 4 & 0 / 4 & 0 / 4 & 0 / 4 \\ \mathrm{Tg}^{\Delta 1.2} & 0 / 7 & 0 / 7 & 0 / 7 & 3 / 7 & 0 / 7 & 0 / 7 & 0 / 7\end{array}$

${ }^{A}$ Eight of nine $\mathrm{Tg}^{2.9}$ mice whose EGFP expression in peripheral T cells was positive were analyzed. 


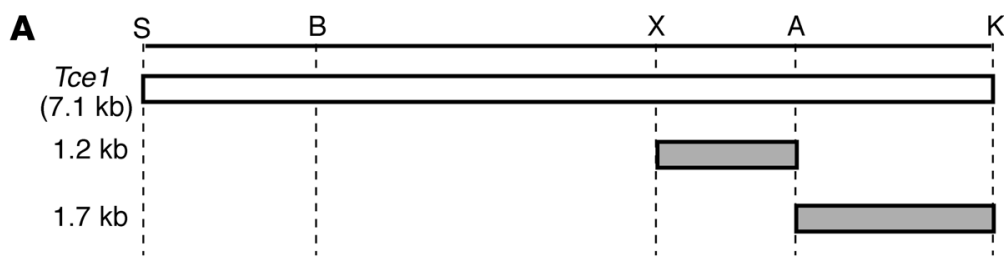

B
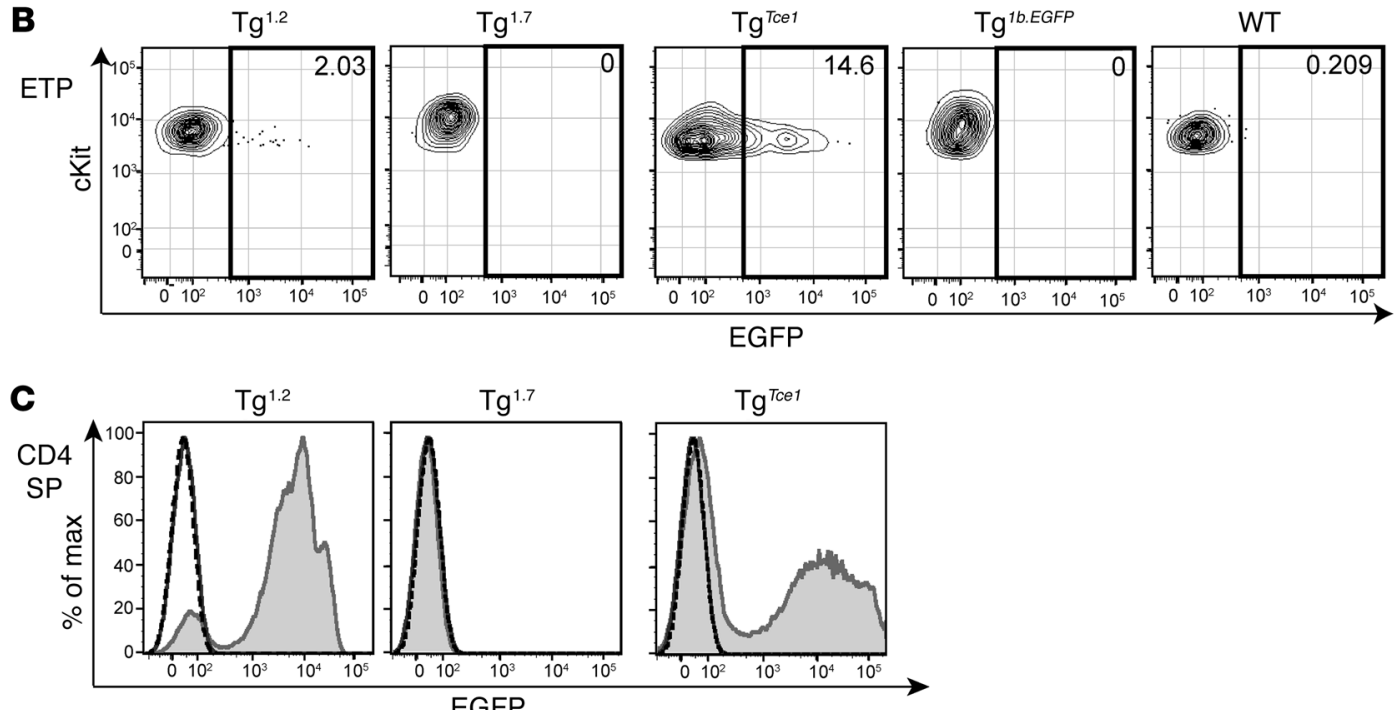

Figure 4. A 1.2-kb fragment of Tce1 drives thymocyte transcription of reporter genes. (A) Illustration of truncated 1.2-kb and 1.7-kb Tce1 fragments. Restriction enzyme recognition sites are shown. EGFP expression in (B) ETP and (C) CD4+CD8- TCR $\beta^{+}$(CD4 SP) cells from Tg ${ }^{1.2}, \mathrm{Tg}^{1.7}, \mathrm{Tg}^{\text {Tce1 }}$, Tg ${ }^{1 \mathrm{1b} . E C F P}$, and wildtype mice. Note that $\mathrm{Tg}^{1.2}$ and $\mathrm{Tg}^{1.7}$ mice represent expression in $\mathrm{F}_{0} \mathrm{Tg}$ mice. Data are representative of 2 independent experiments. The gray shaded histogram represents expression of $\mathrm{Tg}^{1.2}, \mathrm{Tg}^{1.7}$, or $\mathrm{Tg}^{T c e}$, respectively; the solid line histogram indicates the expression of $\mathrm{Tg}^{16 . E C F P}$; and the dashed line histogram represents EGFP expression in wild-type thymocytes.

direct the transcription of a reporter gene in peripheral Th2 cells as well as in thymocytes, although significant induction of EGFP at the Th2 stage was not observed, as it is in endogenous GATA3 (36). This observation indicates that Tce1 activity alone cannot account for all GATA3 expression in Th2 cells and that at least one additional cis element may be required to achieve full GATA3 abundance. In order to clarify the mechanism by which Tce1 contributes to GATA3 expression in Th2 cells, we analyzed EGFP expression of reporter Tg mice bearing Tce1 fragments and found that naive CD4 cells from both $\mathrm{Tg}^{2.9}$ and $\mathrm{Tg}^{1.2}$ mice expressed EGFP (Figure 6 and Table 3). We then stimulated naive CD4 T cells under Th2-polarizing conditions in vitro (see Methods) and, surprisingly, discovered that EGFP expression was eliminated in almost all of the $\mathrm{Tg}^{2.9}$ and $\mathrm{Tg}^{1.2} \mathrm{Th} 2$ cells, comparable to reporter expression in $\operatorname{Tg}^{4.2}$ and $\operatorname{Tg}^{1.7}$ mice (Figure 6 and Table 3). These data show that neither of the initially bisected larger Tce1 fragments is sufficient for the transcription of the EGFP reporter gene in Th2-polarized cells, while Tce1 itself does confer such activity. We concluded that multiple individual cis elements, located within both the $2.9-\mathrm{kb}$ and $4.2-\mathrm{kb}$ fragments, must collaborate to activate Gata3 Th2 cellspecific transcription.

Given that the 1.2-kb enhancer core fragment of Tce1 is necessary for reporter transcription throughout thymocyte development, we asked whether it is also necessary for Th2 transcription. We determined that neither naive CD4 T cells nor Th2-polarized cells that were developed from $\operatorname{Tg}^{\Delta 1.2}$ mice exhibited EGFP fluorescence (Figure $7 \mathrm{~B}$ and Table 3 ). Thus, the 1.2-kb core enhancer region is necessary, but not sufficient, for reporter gene transcription in Th2 cells.

In order to identify which elements within Tce1 are involved in the regulation of Th2 transcription, we generated $\mathrm{Tg}$ mice bearing internal deletions of Tce1 (Figure 7A) and analyzed their expression in naive CD 4 T cells and in Th2 cells (Figure 7B). Since the data indicate that sequences within the $4.2-\mathrm{kb}$ fragment are involved in Th2 transcription and this fragment contains several CNSs (Figure 2A), we examined reporter gene expression after individually deleting either the $2.7-\mathrm{kb}\left(\mathrm{Tg}^{\Delta 2.7}\right)$ or the $1.5-\mathrm{kb}\left(\mathrm{Tg}^{\Delta 1.5}\right)$ segments of Tce1. As shown in Figure 7B and Table 3, naive CD4 T cells from $\operatorname{Tg}^{\Delta 2.7}$ and $\operatorname{Tg}^{\Delta 1.5}$ mice both expressed EGFP. After those cells were stimulated to undergo Th2 differentiation, both genotypes retained EGFP expression (Table 3). These results indicate that the 2.7-kb and 1.5-kb segments of Tce1 are both at least partially redundant for Th2 stimulatory activity and that the $2.7-\mathrm{kb}$ fragment may contribute more robustly than the $1.5-\mathrm{kb}$ fragment to Th2 stimulatory activity in collaboration with the $1.2-\mathrm{kb}$ Tce1 enhancer core fragment.

We also asked whether the 1.7-kb fragment of Tce1 contributes to transcription in Th2 cells by generating additional deletion mutants $\left(\operatorname{Tg}^{\Delta 1.7}\right)$. Naive CD4 $\mathrm{T}$ cells from $\mathrm{Tg}^{\Delta 1.7}$ mice expressed EGFP (Figure 7B and Table 3), as expected. Th2-polarized stim- 
A

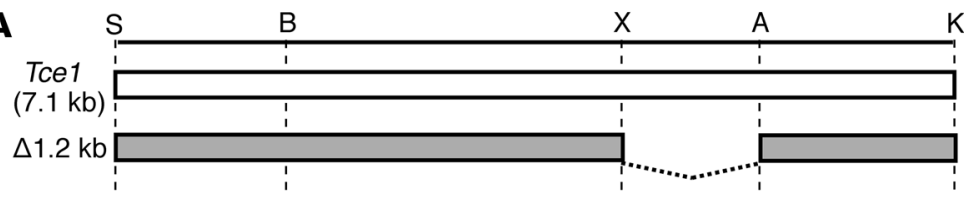

B
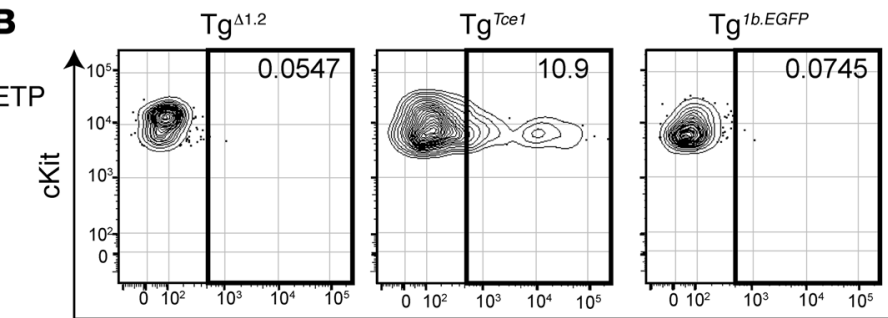

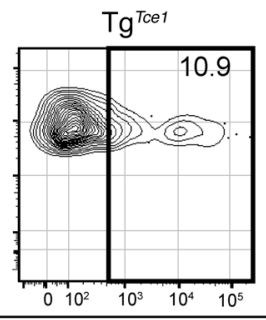

EGFP

C

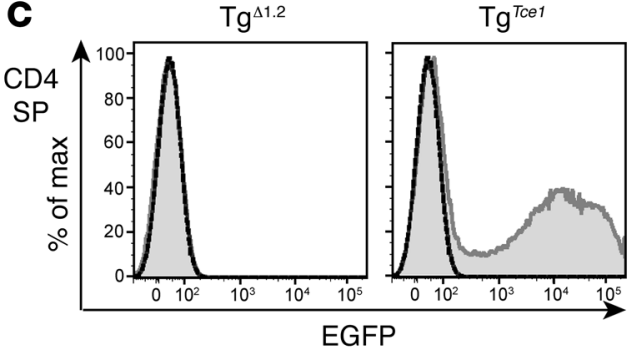

Figure 5. The Tce1 1.2-kb fragment is necessary for thymocyte reporter gene transcription. (A) Illustration of the $1.2-\mathrm{kb}$ deletion mutant Tce 1 fragment. Restriction enzyme recognition sites are shown. EGFP expression in (B) ETP and (C) CD4+CD8-TCR $\beta^{+}$(CD4 SP) cells from $\mathrm{Tg}^{\Delta 1.2}, \mathrm{Tg}^{T c e 1}, \mathrm{Tg}^{16 . E G F P}$, and wild-type mice. Note that $\operatorname{Tg}^{\Delta 1.2}$ mice represent expression in $\mathrm{F}_{0}$ mice, while $\mathrm{Tg}^{\text {Tee }}$ and $\mathrm{Tg}^{1 \mathrm{lb} . E G F P}$ mice are from previously described $\mathrm{Tg}$ lines. Data are representative of 2 independent experiments. The gray shaded histogram represents expression of $\operatorname{Tg}^{\Delta 1.2}$ or $\operatorname{Tg}^{T c e}$, respectively; the solid line histogram indicates expression of $\mathrm{Tg}^{10 . E C F P}$; and the dashed line histogram represents the expression in wild-type mice. ulated T cells also expressed EGFP, although the number of mice that were $\mathrm{EGFP}^{+}$at the Th2 stage was reduced (Table 3). These results suggest that the $1.7-\mathrm{kb}$ region may also modestly contribute to Th2-specific transcription.

We concluded that both the 1.2-kb Tcel enhancer core and either the $2.7-\mathrm{kb}$ or the $1.5-\mathrm{kb}$ fragments within the adjacent 4.2 $\mathrm{kb}$ fragment are required for transcription of reporter genes in Th2 stage cells. These results imply that the transcriptional mechanisms mediated by Tce1 during T cell development are complex, and at least partially redundant through activities residing wholly within Tce1, and, therefore, that the amalgam of cis contributions to $\mathrm{T}$ cell enhancement of Gata3 transcription contained within Tce1 may more closely resemble a locus control region (47) or super-enhancer (48) (i.e., an extended genomic domain harboring clusters of constituent enhancers) rather than a classical monotonic enhancer activity.

TCF-1, HEB, and RBP-J regulate Gata3 transcription by binding within Tce1. Several transcription factors have been proposed as direct or indirect upstream regulators of Gata3 in T cells. For example, TCF-1, a major regulator of T cell developmental activity, which is required for early stages of thymopoiesis (39), appears to not be required for DN2 to DN4, DP, and SP stages (49) but is reinduced for the acquisition of Th2 fate. E-box transcription factor HEB has similarly been implicated as a critical determinant of $\mathrm{T}$ cell developmental decisions $(37,38)$, and $\mathrm{T}$ cell development has been shown to critically require Notch pathway input at multiple stages $(40,50-52)$. Since Tce1 contains dozens of putative transcription factor-binding sites, including sites for all 3 of these proposed upstream regulators, we next examined which of these factors might regulate Gata3 through Tce1.

TCF-1 belongs to the TCF/LEF transcription factor family that binds to DNA through an HMG box and is strongly expressed in $\mathrm{T}$ cells (53). TCF-1 has been shown to be essential for multiple stages of T cell development and for Gata3 transcription (39, 49, 54-56). Enforced expression of TCF-1 induces Gata 3 in Thy $1^{+} \mathrm{CD} 25^{+} \mathrm{T}$ lineage cells when developed in vitro (39). While researchers have reported that TCF-1 binds to the Gata3 promoter (39), it is unknown whether TCF-1 binds to Tce1 to regulate Gata3 expression in T cells. Tce1 contains multiple TCF/LEF-binding sites that are conserved between mice and humans (Figure 8A and Supplemental Figure 7), so we investigated TCF-1's occupancy at those sites by ChIP assays. The binding of TCF-1 to Axin2, a known target gene of TCF-1 in $\mathrm{T}$ cells (39), was used as a positive control (Figure $8 \mathrm{~B}$ ).

We found that TCF-1 bound to site e (Figure 8A and Supplemental Table 3), located within the 1.2-kb enhancer core element, in total thymocytes (Figure $8 \mathrm{~B}$ ). Since more than $80 \%$ of thymocytes are DP cells, we also examined whether TCF- 1 binds to this enhancer at other $\mathrm{T}$ cell developmental stages. As shown in Figure $8 \mathrm{~B}, \mathrm{TCF}-1$ bound to sequences within fragment e (Figure 8A and Supplemental Table 3) in both DN and CD4 thymocytes. Although TCF-1 occupies the Gata3 promoter in DN stage cells (39), we previously demonstrated that a YAC, which includes both Gata3 promoters ( $1 a$ and $1 b$ ) but not Tce1, is insufficient to drive Gata3 transcription in DN cells (36), an observation reconfirmed here (e.g., Figure 3B shows the failure to express EGFP in transgenic mice bearing only the Gata3 $1 \mathrm{~b}$ promoter, $\operatorname{Tg}^{1 b . E G F P}$ ). Therefore, TCF-1 appears to directly control Gata3 expression through the Tce 1 enhancer.

During late T cell development, TCF-1 functions to promote specification to the CD4 lineage by regulating Th-POK in DP cells, while TCF- 1 and Runx 3 collectively repress $C d 4$ in cells that are committed to the CD8 lineage $(49,57)$. Because the absence of TCF-1 during DP through $\mathrm{CD} 4^{+} \mathrm{CD} 8^{\text {lo }}$ intermediate cells does not affect the expression level of Gata3 (49), TCF-1 may not be 

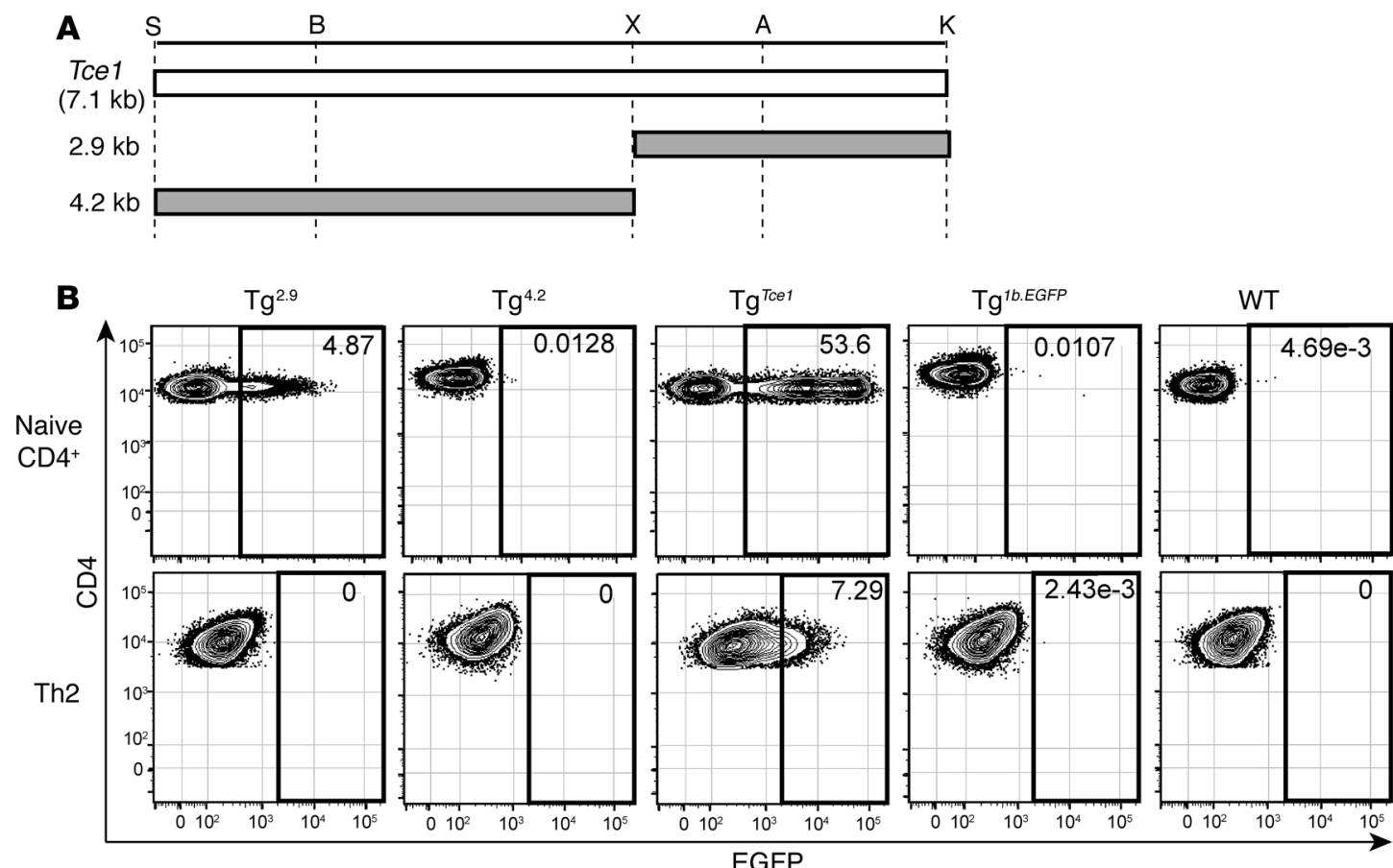

Figure 6. No fragment of Tce1 is alone sufficient for Th2-specific transcription. (A) Illustration of truncated 2.9-kb and 4.2-kb Tce1 fragments. Restriction enzyme recognition sites are shown. (B) EGFP expression in naive CD4+ $\mathrm{T}$ cells and Th2 cells that were generated under Th2-polarizing conditions using in vitro $\mathrm{T}$ cell differentiation. Note that $\mathrm{Tg}^{2.9}$ and $\mathrm{Tg}^{4.2}$ mice are $\mathrm{F}_{0} \mathrm{Tg}$ mice. Data are representative of 2 independent experiments.

a principal component in the induction of Gata3 at those stages. Instead, TCF-1 may function through Tce1 to maintain the expression of Gata3 after the CD4/CD8 lineage determination decision, perhaps by differentially increased binding to sequences within fragment $\mathrm{f}$ (Figure 8A and Supplemental Table 3) to reinforce CD4 commitment (Figure 8B). The binding of TCF-1 to fragments e and $\mathrm{f}$ (Figure 8A and Supplemental Table 3 ) is consistent with previously published ChIP-seq data from total thymocytes (GSE46662 and Supplemental Figure 7) (58).

Transcription factor HEB (59) is an E-box protein belonging to the bHLH family. HEB, like TCF-1, has been implicated in the regulation of various stages of $\mathrm{T}$ cell development (38, 60-62). Since the absence of HEB results in changes in Gata3 levels during T cell development $(37,38)$ and Tce1 contains several E-boxes (putative HEB-binding sites), we asked whether HEB binds to any of those sites. ChIP assays conducted using an anti-HEB serum confirmed HEB binding to the Tcrb locus, a known HEB target gene (Figure 8C and ref. 63). We determined that HEB also binds to region e within the 1.2-kb enhancer core element in DN, DP, and CD4 stage cells (Figure 8C). Gata3 expression increases in HEB-deficient DN3 cells generated from fetal liver hematopoietic progenitors grown on OP9-DL1 feeder layers, and a model proposing how HEB negatively regulates Gata3 has been advanced (37). In contrast, the induction of Gata3 during the DP-to-SP transition is perturbed in the absence of HEB and E2A (38). While HEB forms a homodimer or heterodimer with other E-box proteins (such as E2A) to transactivate target genes (59), it can also heterodimerize with inhibitor of DNA binding (Id) proteins, which prevent E-box factors from binding to DNA (64, 65). Since Id 3 is expressed in thymocytes and plays an important regulatory role there (66), it seems possible that HEB-E2A as well as HEB-Id3 heterodimers could directly contribute to precision tuning of Gata3 expression through Tce1.

Notch is a transmembrane receptor, and Notch signaling is essential, not only for T cell development, but also for cell fate decisions and cellular proliferation in numerous other tissues (52, $67,68)$. After Notch ligand binds to Notch receptor, the cleaved receptor (the intracellular domain of Notch [ICN]) translocates to the nucleus to form a ternary complex with mastermind and transcription factor RBP-J, converting it from a transcriptional repressor to an activator $(69,70)$. During early T cell development and Th2 differentiation, Notch signaling induces Gata3 expression

\section{Table 3. EGFP expression in naive $C D 4^{+} T$ cells and Th2 cells of $F_{0}$ Tg mice}

$\operatorname{Tg}$ No. EGFP+ Tg mice/no. Tg mice (PCR $\left.{ }^{+}\right)$

$\begin{array}{lcc} & \text { Naive CD4 } & \text { Th2 } \\ \mathrm{Tg}^{2.9} & 8 / 8^{\mathrm{A}} & 1 / 8^{\mathrm{A}} \\ \mathrm{Tg}^{4.2} & 0 / 6 & 0 / 6 \\ \mathrm{Tg}^{1.2} & 4 / 7 & 1 / 7 \\ \mathrm{Tg}^{1.7} & 0 / 4 & 0 / 4 \\ \mathrm{Tg}^{\Delta 1.2} & 0 / 7 & 0 / 7 \\ \mathrm{Tg}^{\Delta 2.7} & 5 / 7 & 3 / 7 \\ \mathrm{Tg}^{\Delta 1.5} & 9 / 9^{\mathrm{B}} & 9 / 9^{\mathrm{B}} \\ \mathrm{Tg}^{\Delta 1.7} & 9 / 9^{\mathrm{C}} & 6 / 9^{\mathrm{C}}\end{array}$

${ }^{A}$ Eight of nine $\mathrm{Tg}^{2.9}$ mice, ${ }^{B}$ nine of twenty $\operatorname{Tg}^{\Delta 1.5}$ mice, and ${ }^{C}$ nine of ten $\mathrm{Tg}^{\Delta 1.7}$ mice whose EGFP expression in peripheral T cells was positive were analyzed. 
A

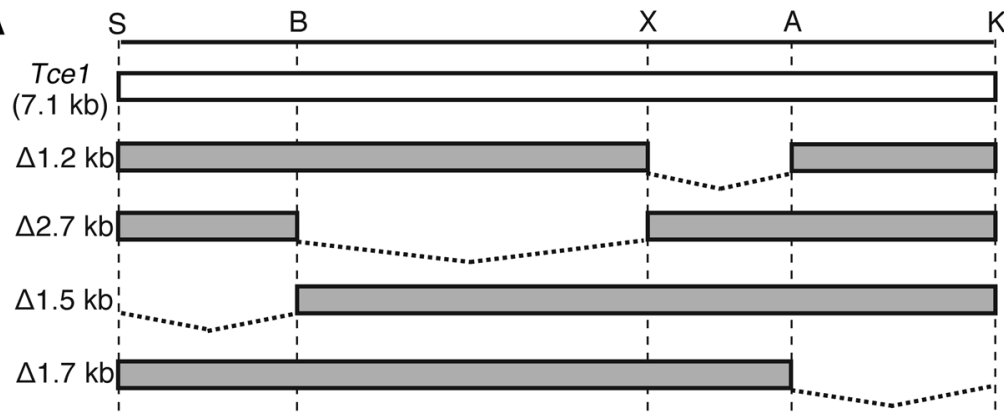

B

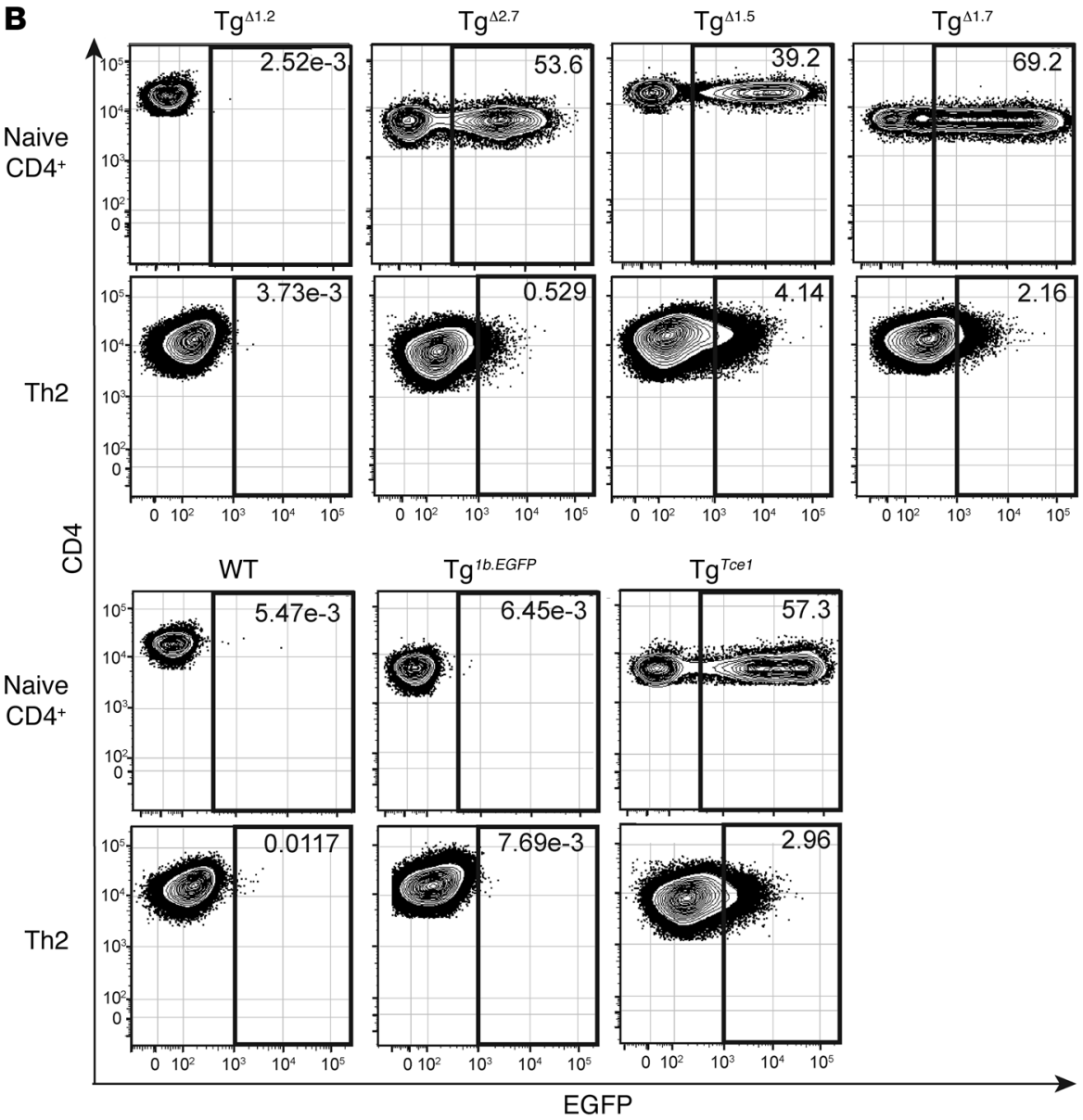

Figure 7. The 1.2-kb Tce1 fragment is necessary for Th2 reporter gene transcription. (A) Illustration of 1.2-kb, 2.7-kb, 1.5-kb, and 1.7-kb deletion mutant Tce1 fragments. Restriction enzyme recognition sites are shown. (B) EGFP expression in naive CD4 ${ }^{+} \mathrm{T}$ cells and Th2 cells from $F_{0} \operatorname{Tg}^{\Delta 1.2}, \operatorname{Tg}^{\Delta 2.7}, \operatorname{Tg}^{\Delta 1.5}$, and $\operatorname{Tg}^{\Delta 1.7}$ mice as well as $\mathrm{Tg}^{1 b . E G F P}$, $\mathrm{Tg}^{\text {Tce1 }}$, and wild-type mice. Data are representative of 2 independent experiments.

expression through Tce1 during early $\mathrm{T}$ cell development but perhaps not during later stages.

Taken together, these data show that at least 3 critical $\mathrm{T}$ cell-affiliated transcription factors, TCF-1, HEB, and CSL/ RBP-J, occupy binding sites within Tce1 at different developmental stages. Since all 3 have been shown to vitally affect $\mathrm{T}$ cell development, it seems likely that these factors and their associated signaling pathways directly modulate Gata 3 expression through their binding to multiple consensus sites within Tcel.

\section{Discussion}

Here, we report that a complex enhancer, encoded by the distant Tce1 activator of transcription factor Gata3, is necessary for $\mathrm{T}$ cell development and is critical for the generation of ETP and for CD4 development, as demonstrated by CRISPR/ Cas-mediated genome editing. This analysis also illuminated the mechanism of action of Tce1 during T cell development and identified several transcription factors that are responsible for engaging this enhancer activity in $\mathrm{T}$ cells.

Many studies have shown that GATA3

$(40,50,71,72)$. Although ICN and CSL/RBP-J have been shown to bind to the Gata3 1a promoter in Th2 cells $(40,50)$, that binding is clearly insufficient for T cell-specific Gata3 expression (36), and it is unknown whether the same factors bind to Tce1. We therefore examined the association of CSL/RBP-J with predicted binding sites within Tce1. CSL/RBP-J binding to the $C d 25$ locus, a robust direct Notch target gene (51), was used as a positive control with an anti-RBP-J antibody in ChIP assays (Figure 8D). We found that CSL/RBP-J bound to sequences within fragments $\mathrm{d}$, e, and $\mathrm{g}$ (Figure 8A and Supplemental Table 3) of Tce1 in DN cells but not in DP cells (Figure 8D). This result is consistent with the observations that Notch signaling is required for early $\mathrm{T}$ cell development and for induction of Gata3 in ETP $(67,68,73)$ but the absence of Notch signaling does not perturb late $\mathrm{T}$ cell development (68). Thus, these results suggest that Notch signaling regulates Gata3 is required at multiple stages for normal $\mathrm{T}$ cell development $(1,2)$. Its abundance varies significantly between stages and is tightly controlled $(5-11,74)$. Although several transcription factors have been proposed as upstream regulators of Gata3 by demonstration that they bind near the Gata3 $1 a$ and/or $1 b$ promoters $(39,40,50$, $75,76)$, a functional requirement for any of those binding sites has not been confirmed by in vivo mutagenesis. Furthermore, the data shown here and previously clearly demonstrate that the promoters alone are insufficient to activate Gata3 expression in T cells (36), while Tcel mediates this activity.

Tcel contains a 1.2-kb enhancer core element, which is sufficient to drive transcription of a reporter gene from the ETP stage through to naive $\mathrm{T}$ cells. While this core element is also required for Th2 transcription, it is insufficient alone for directing Gata 3 transcription in those cells. Additional studies demonstrated that 
A

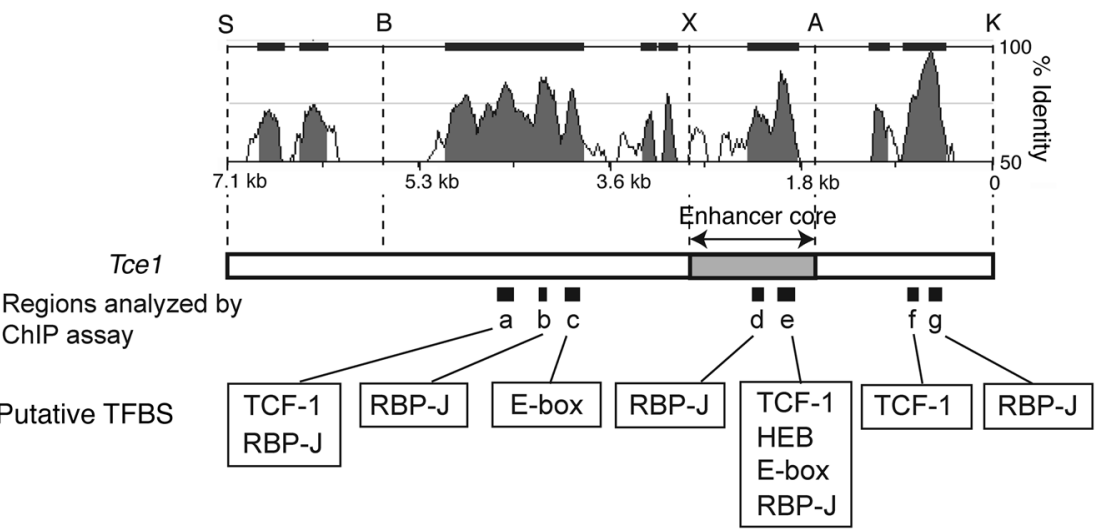

B Total thymocytes
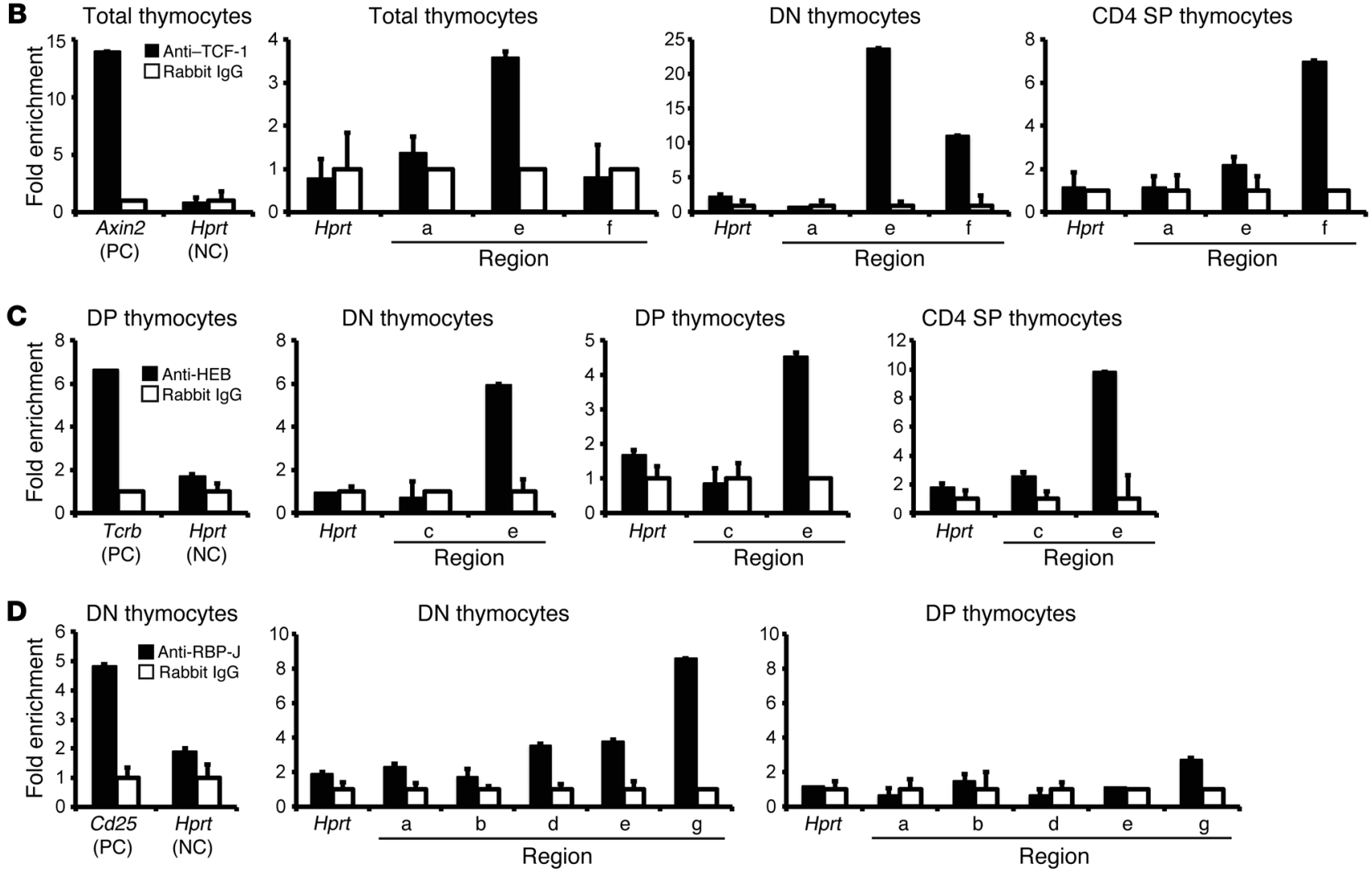

Figure 8. Transcription factors TCF-1, HEB, and RBP-J bind to multiple sites within Tce1. (A) The segments of highest homology between corresponding human and mouse DNA sequences within Tce1 were examined in ChIP assays, and putative transcription factor-binding to these sites were examined. Restriction enzyme sites are shown. The results of ChIP assays comparing immunoprecipitation with either control IgC or (B) anti-TCF-1-, (C) anti-HEB-, or (D) anti-RPB-J-specific antibodies. The graph on the left of each row is the ChIP result from a published positive control locus (PC) and negative control locus (NC) for each antibody $(39,51,63)$. The type of cells used for each assay is shown at the top of each graph. The location of each cluster of binding sites that was analyzed by ChIP assay is shown in $\mathbf{A}$. The error bars represent the mean \pm SD from triplicate qPCR samples. Data are representative of 2 independent experiments.

adjoining 2.7-kb or 1.5-kb fragments within Tce1 must collaborate with the core 1.2-kb fragment to confer Th2-specific enhancement.

During T cell development, multiple distinct combinations of transcription factors are required to regulate specific target genes and guide progenitor cells toward a $\mathrm{T}$ lineage fate. Transcription factors TCF-1, HEB, and RBP-J are each known to be important for early stages of $\mathrm{T}$ cell development (reviewed in ref. 77), and the data herein indicate that each of these regulatory proteins binds to one or more sites within Tce1, each in a developmental stage-specific manner. The demonstration that in vivo deletion of Tce1 results in reduced ETP numbers implies that those factors are involved in Gata3 regulation through this enhancer. Notch signaling has been proposed to activate Gata3 in ETP, although the cis element that is responsible for this activation by Notch has not been previously identified. These data indicate that Notch signaling can activate Gata3 through Tce1 in ETP stage cells.

HEB and TCF-1 are important for CD4 lineage differentiation $(38,49)$. E proteins HEB and E2A function as gatekeepers to 
maintain cells at the DP stage until a functional $\alpha \beta T C R$ is generated (62). E proteins are also required for CD4 lineage choice and for preventing MHC class II-restricted thymocytes from entering the CD8 lineage. During this transition from the DP stage to the SP stage, the absence of E-box proteins or E-box inhibitors Id2 and Id 3 results in upregulated or downregulated Gata3 expression, respectively (38). The finding that genetic ablation of Tce1, which harbors in vivo binding sites for HEB, impaired CD4 T cell development suggests that HEB, possibly acting as an HEB-E2A heterodimeric activator, positively regulates Gata3 expression through Tce1 during the DP-to-SP transition.

In the absence of TCF-1 and LEF-1, CD4 development is impaired and MHC class II-restricted thymocytes are redirected to the CD8 lineage, although their absence does not significantly change the levels of Gata3 in DP and CD $4^{+} \mathrm{CD} 8^{\text {lo }}$ cells (49). TCF-1 and LEF-1 may contribute to the regulation of Gata3 through Tce1 in order to maintain abundant Gata3 expression at the CD4 stage. Alternatively, once bound to Tce1, TCF-1 and LEF-1 may play an architectural role to facilitate the recruitment of other factors, since TCF-1 and LEF-1 contain an HMG domain that has been shown to bend DNA (78).

Interestingly, the finding that phenotypes in Tce1 knockout mice were relatively more subtle than in hematopoietic lineage-specific Gata3 conditional knockout mice (12) implies that there may be a partially redundant enhancer activity somewhere within the extended Gata3 locus (and lying outside of the $1.5 \mathrm{Mb}$ already surveyed; ref. 36). Although Tce1 is sufficient for transcription of a reporter gene throughout $\mathrm{T}$ cell development, we previously concluded that additional cis elements might be required for some stages (for example, for transition from the ETP stage to the DN3 stage or to promote Th2 differentiation) because of differences in the expression pattern of reporter genes and endogenous Gata3 mRNA (36). The result of Tce1 deletion by CRISPR/Cas-mediated genome editing in this study supports the redundant Gata3 T cell enhancer hypothesis.

Enhancer redundancy has been well documented elsewhere. Some such elements exhibit no significant phenotypic effects after loss of the enhancer (e.g., refs. 79, 80). Other studies conclude that enhancers can specify both redundant and essential roles (e.g., ref. 81), as appears to be the case with Tce1, whose loss confers clear deficits in $\mathrm{T}$ cell homeostasis, while not completely abrogating $\mathrm{T}$ cell function. One mechanism that has been proposed for enhancer redundancy is the presence of "shadow enhancers" (refs. 82, 83, and reviewed in ref. 84). According to this hypothesis, two or more enhancers for any given gene may direct similar expression patterns, and those enhancers may appear to be redundant under normal laboratory conditions. However, under stressful conditions (e.g., elevated temperature, food scarcity), environmental influences leading to disrupted function of a single enhancer may perturb normal gene expression. Thus, those shadow enhancers are thought to provide robustness to environmental or genetic perturbation and stress, and the thymus is known to be particularly sensitive to such stresses (85). Therefore, reliable, robust transcription of Gata3 during the ETP and CD4 stages of T cell development may require both $T c e 1$ and a putative shadow enhancer in order to generate appropriate thymic cellular output under conditions that are not usually encountered in the laboratory.
Alternatively, the interaction among multiple cis elements, each containing overlapping but slightly different activity, may be required to produce authentic patterns of gene expression, as previously reported (e.g., refs. 86, 87). For example, Hoxd genes are important for developing hand and foot digits, and cis elements for regulation of the Hoxd genes are distributed over an 800-kb "gene desert." Each element appears to associate with the genes as well as other cis-regulatory elements and function to drive Hoxd gene transcription either quantitatively or qualitatively. Serial deletion of the Hoxd cis elements reveals incomplete redundancy within the cluster (87). The gene desert surrounding the Gata3 locus contains multiple cis elements, not just Tce1, as well as multiple enhancers that regulate the gene in numerous other tissues (refs. 46, 88-91 and our unpublished observations). Intriguingly, Pazin and colleagues demonstrated that a region 736 kb 3 ' to the Gata3 structural gene possesses enhancer-like activity in a T cell-derived cell line using an episomal vector (92). Furthermore, recent genome-wide association studies have revealed that multiple, distinct disease-associated SNPs are located either within or near the GATA3 structural gene and are associated with leukemia (93-95), Hodgkin's lymphoma (96), rhinitis (97), and asthma (98); furthermore, another asthma-associated SNP is located in a gene desert lying $1 \mathrm{Mb} 3$ ' to GATA3 (99). The underlying hypothesis in all of these studies is that those SNPs may reside in yet-to-be-defined cis-regulatory elements and may affect GATA3 expression in those T cell-related and/or aberrant GATA3 expression-related diseases. Therefore, Tce1 and other currently undefined cis elements may contain partially overlapping activity and interact with one another to coordinately regulate Gata3 transcription during $\mathrm{T}$ cell development.

Tce1, which consists of the enhancer core and accessory cis elements, is necessary for ETP and CD4 T cell development and Gata3 expression. We showed that TCF-1, HEB, and RBP-J (as well as other factors that were not examined in this study) occupy this enhancer and regulate Gata3 during T cell development. Understanding Tce1 function provides an essential pathway to elucidating the direct temporal regulation of Gata3, a critical, central regulatory protein that is required for $\mathrm{T}$ cell development. The present study should help to better define and further integrate transcriptional networks that regulate Gata3 during T cell development. Further studies addressing Gata3 regulation and function would provide important advances in our understanding of $\mathrm{T}$ cell development and should lead to clarification of the mechanisms underlying the molecular basis for the multiple diseases of hematopoietic origin in which GATA3 is implicated, such as leukemia and asthma.

\section{Methods}

Mice. The locus surrounding Tce1 was edited using CRISPR/Cas9, as described previously (42). gRNA sequences corresponding to sequences surrounding the $7.1 \mathrm{kbp}$ that define the boundaries of Tce1 (Supplemental Figure 1A) were cloned into the BbsI site of the bicistronic expression vector px330 (Addgene; the gift of Feng Zhang, Broad Institute of MIT and Harvard, Cambridge, Massachusetts, USA; ref. 100), which expresses Cas9 and single gRNA. The two CRISPR/Cas9gRNA plasmids were coinjected with single-stranded oligos containing loxP sequences, an EcoRI site, and 60-bp homology arms (Supplemental Figure 1B) into the pronuclei of fertilized eggs. The injected zygotes 
were transferred into the oviduct of pseudopregnant ICR females at 1.0 to $1.5 \mathrm{dpc}$. Mice were genotyped by PCR using primers shown in Supplemental Figure 1A. The deletion of Tce1 was confirmed by DNA sequencing of the PCR product (Supplemental Figure 2).

$\mathrm{Tg}^{\text {Tcel }}$ and $\operatorname{Tg}^{1 b . E G F P}$ mice were established as previously described (36), and Tg lines were used in this study. Founder Tg mice containing various truncated Tce1 fragments were generated using standard techniques in the University of Michigan Transgenic Animal Model Core. Plasmid DNAs were microinjected into $(\mathrm{C} 57 \mathrm{BL} / 6 \mathrm{~J} \times \mathrm{SJL}) \mathrm{F}_{2}$ fertilized eggs. Those founder $\mathrm{Tg}$ mice were used for analysis instead of establishing $\mathrm{Tg}$ lines.

Plasmid construction. Details are provided in the Supplemental Methods.

Flow cytometry. To analyze expression of the EGFP reporter gene in the various $\mathrm{Tg}$ founder mice, single-cell suspensions of thymocytes, bone marrow cells, splenocytes, lymph node cells, or peripheral blood were incubated with Fc Block (BD Bioscience). Before incubation, splenocytes and peripheral blood were hemolyzed with ammonium chloride. Cells were stained with a variety of antibodies as previously described (36), washed, and analyzed on a FACSCanto II, Fortessa, or FACSAria III (BD Biosciences). Dead cells were excluded by DAPI or propidium iodide. Immature $\mathrm{T}$ cells were analyzed as previously described (12). The following antibodies were purchased from BioLegend, eBioscience, and/or BD: B220 (RA3-6B2; BioLegend and eBioscience), CD3 (17A2; BioLegend and eBioscience), CD8a (536.7; BioLegend and eBioscience), CD11b (M1/70; BioLegend and eBioscience), CD11c, (N418; BioLegend and eBioscience), CD19 (1D3; BioLegend and eBioscience), CD25 (PC61.5; BioLegend and eBioscience), cKit (2B8; BioLegend and eBioscience), Gr1 (RB6-8C5; BioLegend and eBioscience), NK1.1 (PK136; eBioscience), TCR $\beta$ (H57-597; BioLegend and eBioscience), TCR $\gamma / \delta$ (GL3; BioLegend, eBioscience, and BD), TER119 (TER-119; BioLegend and eBioscience), and Thy1.2 (53-2.1; BioLegend).

For every experiment in which EGFP expression was analyzed, a LinearFlow Green Flow Cytometry Intensity Calibration Kit (Molecular Probes) was used. These calibration beads were excited by 488-nm laser, and fluorescence measurements were performed in the same manner as those for EGFP in order to confirm that the intensity of EGFP PMT voltage was at comparable levels in all experiments. Acquired data were analyzed using FlowJo software (Tree Star Inc.).

To sort each stage of thymocytes for ChIP assay, cells were incubated with Fc Block and stained with PE-Cy7-anti-CD4 (clone RM4-5; BioLegend), APC-anti-CD8a (clone 53-6.7; BioLegend), and PerCPCy5.5-anti-TCR $\beta$ (clone H57-597; BioLegend). DAPI was used as a dead cell marker. DN $\left(\mathrm{CD}^{-} \mathrm{CD}^{-}\right)$cells, $\mathrm{DP}\left(\mathrm{CD}^{+} \mathrm{CD}^{+}\right)$cells, and $\mathrm{CD} 4 \mathrm{SP}$ $\left(\mathrm{CD} 4^{+} \mathrm{CD} 8{ }^{-} \mathrm{TCR} \beta^{+}\right)$cells were sorted in a FACSAria III (BD Bioscience).

Quantitative RT-PCR. Quantitative RT-PCR (qRT-PCR) was performed as described previously (74).

In vitro $C D 4 \mathrm{~T}$ cell differentiation. $\mathrm{CD} 4{ }^{+} \mathrm{CD} 25^{-}$lymph node cells were purified using the Dynal Mouse CD4-Negative Isolation Kit (Invitrogen) in combination with affinity-purified anti-mouse CD25 antibody (PC61.5; eBioscience or BioLegend) and cultured as pre- viously described (36). Briefly, isolated CD4 cells were stimulated with plate-bound anti-CD3 $\varepsilon$ antibody $(10 \mu \mathrm{g} / \mathrm{ml}$; $145-2 \mathrm{C} 11$; BD Biosciences) and anti-CD28 antibody (10 g/ml; 37.51; BD Biosciences). To induce Th2-polarizing conditions, $10 \mu \mathrm{g} / \mathrm{ml}$ anti-IFN- $\gamma$ antibody (XMG1.2; BD Biosciences), $10 \mu \mathrm{g} / \mathrm{ml}$ anti-IL-12 antibody (C17.8; BD Biosciences), $10 \mathrm{ng} / \mathrm{ml}$ recombinant human IL-2 (200-02, PeproTech), and $10 \mathrm{ng} / \mathrm{ml}$ recombinant mouse IL-4 (554432, BD Pharmingen) were added. On day 4 of culture, stimulation was stopped and the cells were diluted. On day 6, cells were restimulated with plate-bound anti-CD $3 \varepsilon$ and anti-CD28 antibodies $(3 \mu \mathrm{g} / \mathrm{ml}$ each) for 6 hours. Cells were harvested, and we analyzed EGFP expression by flow cytometry as previously described (36). A small fraction of harvested cells was used for RNA extraction to confirm in vitro $\mathrm{T}$ cell differentiation by measuring the expression of cytokine mRNAs (Il4 and Ifng) and endogenous Gata3 mRNA by qRT-PCR (data not shown).

ChIP. Details are provided in the Supplemental Methods.

Prediction of putative transcription factor-binding sites. A search for putative transcription factor-binding sites in Tce1 was performed using rVISTA 2.0 (http://rvista.dcode.org) (101) or rVISTA (http://genome. lbl.gov/vista/rvista/submit.shtml) (102).

Statistics. Data were analyzed by 2 -tailed Student's $t$ test. A P value of less than 0.05 was considered significant.

Study approval. All animal experiments were approved by and conducted in accordance with the guidelines of the Committee on the Use and Care of Animals of the University of Michigan or the Animal Experiment Committee of Tsukuba University.

\section{Author contributions}

SO devised and executed experiments and wrote the paper. SM and $\mathrm{HO}$ performed and interpreted experiments. HO and ST devised and interpreted experiments. $\mathrm{MH}$ executed experiments. CJK performed experiments and wrote the paper. TH devised and performed experiments and wrote the paper. JDE designed experimental strategy, interpreted experiments, and wrote the paper.

\section{Acknowledgments}

We thank Ivan Maillard for critical reading of the manuscript and Wanda Filipiak and Galina Gavrilina for the generation of Tg mice at the Transgenic Animal Model Core of the University of Michigan's Biomedical Research Core Facilities. Core support was provided by the University of Michigan Comprehensive Cancer Center (NIH CA46592) and by the George M. O’Brien Renal Core Center (NIH DK08194). This study was supported by postdoctoral fellowships from the Cancer Research Institute (to S. Ohmura) and the Lymphoma Research Foundation (to C.J. Ku) and by a grant from the NIH (R01AI094642 to J.D. Engel and T. Hosoya).

Address correspondence to: James Douglas Engel, Department of Cell and Developmental Biology, University of Michigan Medical School, 3052 BSRB, 109 Zina Pitcher Place, Ann Arbor, Michigan 48109A-2200, USA. Phone: 734.615.7509; E-mail: engel@umich.edu.
1. Singer A, Adoro S, Park JH. Lineage fate and intense debate: myths, models and mechanisms of CD4- versus CD8-lineage choice. Nat Rev Immunol. 2008;8(10):788-801.
2. Hosoya T, Maillard I, Engel JD. From the cradle to the grave: activities of GATA-3 throughout T-cell development and differentiation. Immunol Rev. 2010;238(1):110-125.
3. Yamamoto M, Ko LJ, Leonard MW, Beug H, Orkin SH, Engel JD. Activity and tissue-specific expression of the transcription factor NF-E1 multigene family. Genes Dev. 1990;4(10):1650-1662. 
4. Ko LJ, Yamamoto M, Leonard MW, George KM, Ting P, Engel JD. Murine and human T-lymphocyte GATA-3 factors mediate transcription through a cis-regulatory element within the human T-cell receptor delta gene enhancer. $\mathrm{Mol}$ Cell Biol. 1991;11(5):2778-2784.

5. Zheng W, Flavell RA. The transcription factor GATA-3 is necessary and sufficient for Th2 cytokine gene expression in CD4 T cells. Cell. 1997;89(4):587-596.

6. Zhang DH, Cohn L, Ray P, Bottomly K, Ray A. Transcription factor GATA-3 is differentially expressed in murine Th1 and Th2 cells and controls Th2-specific expression of the interleukin-5 gene. J Biol Chem. 1997;272(34):21597-21603.

7. Hendriks RW, Nawijn MC, Engel JD, van Doorninck H, Grosveld F, Karis A. Expression of the transcription factor GATA-3 is required for the development of the earliest $\mathrm{T}$ cell progenitors and correlates with stages of cellular proliferation in the thymus. Eur J Immunol.1999;29(6):1912-1918.

8. Hernández-Hoyos G, Anderson MK, Wang C, Rothenberg EV, Alberola-Ila J. GATA-3 expression is controlled by TCR signals and regulates $\mathrm{CD} 4 / \mathrm{CD} 8$ differentiation. Immunity. 2003;19(1):83-94.

9. Sambandam A, et al. Notch signaling controls the generation and differentiation of early $\mathrm{T}$ lineage progenitors. Nat Immunol. 2005;6(7):663-670.

10. David-Fung E-S, et al. Progression of regulatory gene expression states in fetal and adult pro-T-cell development. Immunol Rev. 2006;209:212-236.

11. Tydell CC, David-Fung ES, Moore JE, Rowen L, Taghon T, Rothenberg EV. Molecular dissection of prethymic progenitor entry into the Tlymphocyte developmental pathway. JImmunol. 2007;179(1):421-438.

12. Hosoya T, et al. GATA-3 is required for early $\mathrm{T}$ lineage progenitor development. JExp Med. 2009;206(13):2987-3000.

13. Garcia-Ojeda ME, et al. GATA-3 promotes T-cell specification by repressing $\mathrm{B}$-cell potential in pro-T cells in mice. Blood. 2013;121(10):1749-1759.

14. Pai S-Y, Truitt ML, Ting C-N, Leiden JM, Glimcher LH, Ho I-C. Critical roles for transcription factor GATA-3 in thymocyte development. Immunity. 2003;19(6):863-875.

15. Wang L, et al. Distinct functions for the transcription factors GATA-3 and ThPOK during intrathymic differentiation of CD4(+) T cells. Nat Immunol. 2008;9(10):1122-1130.

16. Pai S-Y, Truitt ML, Ho I-C. GATA-3 deficiency abrogates the development and maintenance of T helper type 2 cells. Proc Natl Acad Sci US A. 2004;101(7):1993-1998.

17. Zhu J, et al. Conditional deletion of Gata3 shows its essential function in $\mathrm{T}(\mathrm{H}) 1-\mathrm{T}(\mathrm{H}) 2$ responses. Nat Immunol. 2004;5(11):1157-1165.

18. Tai TS, Pai SY, Ho IC. GATA-3 regulates the homeostasis and activation of $\mathrm{CD} 8^{+} \mathrm{T}$ cells. J Immunol. 2013;190(1):428-437.

19. Wang T, et al. GATA-3 expression identifies a high-risk subset of PTCL, NOS with distinct molecular and clinical features. Blood. 2014;123(19):3007-3015.

20. Hoyler $\mathrm{T}$, et al. The transcription factor GATA-3 controls cell fate and maintenance of type 2 innate lymphoid cells. Immunity.
2012;37(4):634-648.

21. Mjosberg J, et al. The transcription factor GATA3 is essential for the function of human type 2 innate lymphoid cells. Immunity. 2012;37(4):649-659.

22. Yagi $R$, et al. The transcription factor GATA3 is critical for the development of all IL-7R $\alpha$ expressing innate lymphoid cells. Immunity. 2014;40(3):378-388.

23. Samson SI, et al. GATA-3 promotes maturation, IFN- $\gamma$ production, and liver-specific homing of NK cells. Immunity. 2003;19(5):701-711.

24. Vosshenrich CA, et al. A thymic pathway of mouse natural killer cell development characterized by expression of GATA-3 and CD127. Nat Immunol. 2006;7(11):1217-1224.

25. Banerjee A, Northrup D, Boukarabila H, Jacobsen SE, Allman D. Transcriptional repression of Gata3 is essential for early B cell commitment. Immunity. 2013;38(5):930-942.

26. Chen D, Zhang G. Enforced expression of the GATA-3 transcription factor affects cell fate decisions in hematopoiesis. Exp Hematol. 2001;29(8):971-980.

27. Nawijn MC, et al. Enforced expression of GATA-3 during $\mathrm{T}$ cell development inhibits maturation of CD8 single-positive cells and induces thymic lymphoma in transgenic mice. J Immunol. 2001;167(2):715-723.

28. Taghon T, De Smedt M, Stolz F, Cnockaert M, Plum J, Leclercq G. Enforced expression of GATA-3 severely reduces human thymic cellularity. JImmunol. 2001;167(8):4468-4475.

29. Anderson MK, Hernandez-Hoyos G, Dionne CJ, Arias AM, Chen D, Rothenberg EV. Definition of regulatory network elements for T cell development by perturbation analysis with PU. Dev Biol. 2002;246(1):103-121.

30. Taghon T, Yui MA, Rothenberg EV. Mast cell lineage diversion of $\mathrm{T}$ lineage precursors by the essential T cell transcription factor GATA-3. Nat Immunol. 2007;8(8):845-855.

31. Ano S, et al. Transcription factors GATA-3 and ROR $\gamma \mathrm{t}$ are important for determining the phenotype of allergic airway inflammation in a murine model of asthma. J Immunol. 2013;190(3):1056-1065.

32. KleinJan A, et al. Enforced expression of Gata 3 in T cells and group 2 innate lymphoid cells increases susceptibility to allergic airway inflammation in mice. J Immunol. 2014;192(4):1385-1394.

33. Atayar C, Poppema S, Blokzijl T, Harms G, Boot M, van den Berg A. Expression of the T-cell transcription factors, GATA-3 and T-bet, in the neoplastic cells of Hodgkin lymphomas. Am J Pathol. 2005;166(1):127-134.

34. Stanelle J, Doring C, Hansmann ML, Kuppers R. Mechanisms of aberrant GATA3 expression in classical Hodgkin lymphoma and its consequences for the cytokine profile of Hodgkin and Reed/Sternberg cells. Blood. 2010;116(20):4202-4211.

35. Van Esch H, et al. GATA3 haplo-insufficiency causes human HDR syndrome. Nature. 2000;406(6794):419-422.

36. Hosoya-Ohmura S, et al. An NK and T cell enhancer lies 280 kilobase pairs $3^{\prime}$ to the gata3 structural gene. Mol Cell Biol. 2011; 31(9):1894-1904.

37. Braunstein M, Anderson MK. HEB-deficient $\mathrm{T}$-cell precursors lose T-cell potential and adopt an alternative pathway of differentiation. $\mathrm{Mol}$ Cell Biol. 2011;31(5):971-982.

38. Jones-Mason ME, Zhao X, Kappes D, Lasorella A, Iavarone A, Zhuang Y. E protein transcription factors are required for the development of CD $4(+)$ lineage T cells. Immunity. 2012;36(3):348-361.

39. Weber BN, et al. A critical role for TCF-1 in T-lineage specification and differentiation. Nature. 2011;476(7358):63-68.

40. Amsen D, et al. Direct regulation of gata3 expression determines the $\mathrm{T}$ helper differentiation potential of Notch. Immunity. 2007;27(1):89-99.

41. Notani D, et al. Global regulator SATB1 recruits beta-catenin and regulates $\mathrm{T}(\mathrm{H}) 2$ differentiation in Wnt-dependent manner. PLoS Biol. 2010;8(1):e1000296.

42. Yang H, Wang H, Shivalila CS, Cheng AW, Shi L, Jaenisch R. One-step generation of mice carrying reporter and conditional alleles by CRISPR/ Cas-mediated genome engineering. Cell. 2013;154(6):1370-1379.

43. Kuhn R, Schwenk F, Aguet M, Rajewsky K. Inducible gene targeting in mice. Science. 1995;269(5229):1427-1429.

44. Fujii W, Kawasaki K, Sugiura K, Naito K. Efficient generation of large-scale genome-modified mice using gRNA and CAS9 endonuclease. Nucleic Acids Res. 2013;41(20):e187.

45. Gerberick GF, Cruse LW, Miller CM, Sikorski EE, Ridder GM. Selective modulation of T cell memory markers CD62L and CD44 on murine draining lymph node cells following allergen and irritant treatment. Toxicol Appl Pharmacol. 1997;146(1):1-10.

46. George KM, et al. Embryonic expression and cloning of the murine GATA-3 gene. Development. 1994;120(9):2673-2686.

47. Grosveld F, van Assendelft GB, Greaves DR, Kollias G. Position-independent, high-level expression of the human beta-globin gene in transgenic mice. Cell. 1987;51(6):975-985.

48. Whyte WA, et al. Master transcription factors and mediator establish super-enhancers at key cell identity genes. Cell. 2013;153(2):307-319.

49. Steinke FC, et al. TCF-1 and LEF-1 act upstream of Th-POK to promote the CD4(+) T cell fate and interact with Runx3 to silence Cd4 in CD8(+) T cells. Nat Immunol. 2014;15(7):646-656.

50. Fang TC, Yashiro-Ohtani Y, Del Bianco C, Knoblock DM, Blacklow SC, Pear WS. Notch directly regulates Gata3 expression during T helper 2 cell differentiation. Immunity. 2007;27(1):100-110.

51. Maillard I, et al. The requirement for Notch signaling at the beta-selection checkpoint in vivo is absolute and independent of the pre-T cell receptor. J Exp Med. 2006;203(10):2239-2245.

52. Maillard I, Fang T, Pear WS. Regulation of lymphoid development, differentiation, and function by the Notch pathway. Annu Rev Immunol 2005;23:945-974.

53. van de Wetering M, Oosterwegel M, Dooijes D, Clevers H. Identification and cloning of TCG-1, a T lymphocyte-specific transcription factor con- 
taining a sequence-specific HMG box. EMBO J. 1991;10(1):123-132.

54. Germar K, et al. T-cell factor 1 is a gatekeeper for T-cell specification in response to Notch signaling. Proc Natl Acad Sci U S A. 2011;108(50):20060-20065.

55. Verbeek S, et al. An HMG-box-containing T-cell factor required for thymocyte differentiation. Nature. 1995;374(6517):70-74.

56 . Yu Y, et al. Bcl11a is essential for lymphoid development and negatively regulates p53. J Exp Med. 2012;209(13):2467-2483.

57. Setoguchi R, et al. Repression of the transcription factor Th-POK by Runx complexes in cytotoxic T cell development. Science. 2008;319(5864):822-825.

58. Li L, et al. A far downstream enhancer for murine Bcl11b controls its T-cell specific expression. Blood. 2013;122(6):902-911.

59. Hu JS, Olson EN, Kingston RE. HEB, a helixloop-helix protein related to E2A and ITF2 that can modulate the DNA-binding ability of myogenic regulatory factors. Mol Cell Biol. 1992;12(3):1031-1042.

60. Barndt R, Dai MF, Zhuang Y. A novel role for HEB downstream or parallel to the pre-TCR signaling pathway during $\alpha \beta$ thymopoiesis. J Immunol. 1999;163(6):3331-3343.

61. Wojciechowski J, Lai A, Kondo M, Zhuang Y. E2A and HEB are required to block thymocyte proliferation prior to pre-TCR expression. JImmunol. 2007;178(9):5717-5726.

62. Jones ME, Zhuang Y. Acquisition of a functional $\mathrm{T}$ cell receptor during T lymphocyte development is enforced by HEB and E2A transcription factors. Immunity. 2007;27(6):860-870.

63. Kawai Y, et al. Claudin- 4 induction by E-protein activity in later stages of $\mathrm{CD} 4 / 8$ doublepositive thymocytes to increase positive selection efficiency. Proc Natl Acad Sci U S A. 2011;108(10):4075-4080.

64. Benezra R, Davis RL, Lockshon D, Turner DL, Weintraub $\mathrm{H}$. The protein Id: a negative regulator of helix-loop-helix DNA binding proteins. Cell. 1990;61(1):49-59.

65. Kee BL. E and ID proteins branch out. Nat Rev Immunol. 2009;9(3):175-184.

66. Rivera RR, Johns CP, Quan J, Johnson RS, Murre C. Thymocyte selection is regulated by the helix-loop-helix inhibitor protein, Id3. Immunity. 2000;12(1):17-26.

67. Radtke $\mathrm{F}$, et al. Deficient $\mathrm{T}$ cell fate specification in mice with an induced inactivation of Notch1. Immunity. 1999;10(5):547-558.

68. Wolfer A, et al. Inactivation of Notch 1 in immature thymocytes does not perturb CD4 or CD8T cell development. Nat Immunol. 2001;2(3):235-241.

69. Wu L, Aster JC, Blacklow SC, Lake R, ArtavanisTsakonas S, Griffin JD. MAML1, a human homologue of Drosophila mastermind, is a transcriptional co-activator for NOTCH receptors. Nat Genet. 2000;26(4):484-489.

70. Hsieh JJ, Henkel T, Salmon P, Robey E, Peterson MG, Hayward SD. Truncated mammalian Notch1 activates CBF1/RBPJk-repressed genes by a mechanism resembling that of Epstein-Barr virus EBNA2. Mol Cell Biol. 1996;16(3):952-959.

71. Höflinger S, et al. Analysis of Notch1 function by in vitro $\mathrm{T}$ cell differentiation of Pax 5 mutant lymphoid progenitors. JImmunol. 2004;173(6):3935-3944.

72. Rothenberg EV, Taghon T. Molecular genetics of T cell development. Annu Rev Immunol. 2005;23:601-649.

73. Guo Y, Maillard I, Chakraborti S, Rothenberg EV, Speck NA. Core binding factors are necessary for natural killer cell development, and cooperate with Notch signaling during $\mathrm{T}$ cell specification. Blood. 2008;112(3):480-492.

74. Ku CJ, Hosoya T, Maillard I, Engel JD. GATA-3 regulates hematopoietic stem cell maintenance and cell-cycle entry. Blood. 2012;119(10):2242-2251.

75. Maurice D, Hooper J, Lang G, Weston K. c-Myb regulates lineage choice in developing thymocytes via its target gene Gata3. EMBO J. 2007;26(15):3629-3640.

76. Yang XO, et al. Requirement for the basic helix-loop-helix transcription factor Dec2 in initial TH2 lineage commitment. Nat Immunol. 2009;10(12):1260-1266.

77. Yui MA, Rothenberg EV. Developmental gene networks: a triathlon on the course to $T$ cell identity. Nat Rev Immunol. 2014;14(8):529-545.

78. Giese K, Cox J, Grosschedl R. The HMG domain of lymphoid enhancer factor 1 bends DNA and facilitates assembly of functional nucleoprotein structures. Cell.1992;69(1):185-195.

79. Bebin AG, et al. In vivo redundant function of the 3 ' IgH regulatory element HS3b in the mouse. J Immunol. 2010;184(7):3710-3717.

80. Cretekos CJ, Wang Y, Green ED, Martin JF, Behringer RR. Regulatory divergence modifies limb length between mammals. Genes Dev . 2008;22(2):141-151.

81. Xiong N, Kang C, Raulet DH. Redundant and unique roles of two enhancer elements in the TCRgamma locus in gene regulation and gammadelta $\mathrm{T}$ cell development. Immunity. 2002;16(3):453-463.

82. Hong JW, Hendrix DA, Levine MS. Shadow enhancers as a source of evolutionary novelty. Science. 2008;321(5894):1314.

83. Chen JC, Ramachandran R, Goldhamer DJ. Essential and redundant functions of the MyoD distal regulatory region revealed by targeted mutagenesis. Dev Biol. 2002;245(1):213-223.

84. Barolo S. Shadow enhancers: frequently asked questions about distributed cis-regulatory information and enhancer redundancy. Bioessays. 2012;34(2):135-141.

85. Gruver AL, Sempowski GD. Cytokines, leptin, and stress-induced thymic atrophy. J Leukoc Biol. 2008;84(4):915-923.

86. Perry MW, Boettiger AN, Levine M. Multiple enhancers ensure precision of gap gene-expression patterns in the Drosophila embryo. Proc Natl Acad Sci U S A. 2011;108(33):13570-13575.

87. Montavon T, et al. A regulatory archipelago controls Hox genes transcription in digits. Cell. 2011;147(5):1132-1145.

88. Hasegawa SL, Moriguchi T, Rao A, Kuroha T, Engel JD, Lim K-C. Dosage-dependent rescue of definitive nephrogenesis by a distant Gata3 enhancer. Dev Biol. 2007;301(2):568-577.

89. Lakshmanan G, Lieuw KH, Grosveld F, Engel JD. Partial rescue of GATA-3 by yeast artificial chromosome transgenes. Dev Biol. 1998;204(2):451-463.

90. Lakshmanan G, et al. Localization of distant urogenital system-, central nervous system-, and endocardium-specific transcriptional regulatory elements in the GATA-3 locus. Mol Cell Biol. 1999;19(2):1558-1568.

91. Lieuw KH, Li G, Zhou Y, Grosveld F, Engel JD. Temporal and spatial control of murine GATA-3 transcription by promoter-proximal regulatory elements. Dev Biol. 1997;188(1):1-16.

92. De S, Wurster AL, Precht P, Wood WH 3rd, Becker KG, Pazin MJ. Dynamic BRG1 recruitment during $\mathrm{T}$ helper differentiation and activation reveals distal regulatory elements. Mol Cell Biol. 2011;31(7):1512-1527.

93. Perez-Andreu V, et al. Inherited GATA3 variants are associated with Ph-like childhood acute lymphoblastic leukemia and risk of relapse. Nat Genet. 2013;45(12):1494-1498.

94. Perez-Andreu V, et al. A genome-wide association study of susceptibility to acute lymphoblastic leukemia in adolescents and young adults. Blood. 2015;125(4):680-686.

95. Migliorini G, et al. Variation at 10p12.2 and 10 p14 influences risk of childhood B-cell acute lymphoblastic leukemia and phenotype. Blood. 2013;122(19):3298-3307.

96. Enciso-Mora V, et al. A genome-wide association study of Hodgkin's lymphoma identifies new susceptibility loci at 2p16. Nat Genet. 2010;42(12):1126-1130.

97. Huebner M, Kim DY, Ewart S, Karmaus W, Sadeghnejad A, Arshad SH. Patterns of GATA3 and IL13 gene polymorphisms associated with childhood rhinitis and atopy in a birth cohort. JAllergy Clin Immunol. 2008;121(2):408-414.

98. Pykalainen M, et al. Association analysis of common variants of STAT6, GATA3, and STAT4 to asthma and high serum IgE phenotypes. JAllergy Clin Immunol. 2005;115(1):80-87.

99. Hirota T, et al. Genome-wide association study identifies three new susceptibility loci for adult asthma in the Japanese population. Nat Genet. 2011;43(9):893-896.

100.Cong $\mathrm{L}$, et al. Multiplex genome engineering using CRISPR/Cas systems. Science. 2013; 339(6121):819-823.

101.Loots GG, Ovcharenko I. rVISTA 2.0: evolutionary analysis of transcription factor binding sites. Nucleic Acids Res. 2004; 32(Web Server issue):W217-W221.

102. Loots GG, Ovcharenko I, Pachter L, Dubchak I, Rubin EM. rVista for comparative sequencebased discovery of functional transcription factor binding sites. Genome Res. 2002;12(5):832-839. 